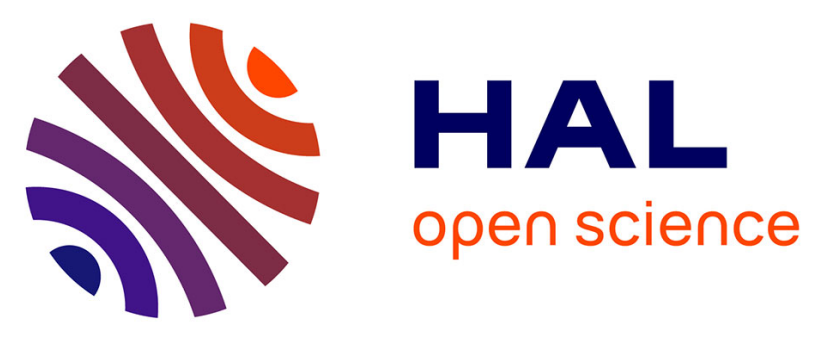

\title{
Design of thermoresponsive elastin-like glycopolypeptides for selective lectin binding and sorting
}

Lourdes Monica M Bravo Anaya, Rosine Petitdemange, Marie Rosselin, Emmanuel Ibarboure, Bertrand Garbay, Elisabeth Garanger, Timothy

Deming, Sébastien Lecommandoux

\section{To cite this version:}

Lourdes Monica M Bravo Anaya, Rosine Petitdemange, Marie Rosselin, Emmanuel Ibarboure, Bertrand Garbay, et al.. Design of thermoresponsive elastin-like glycopolypeptides for selective lectin binding and sorting. Biomacromolecules, 2021, 21 (1), pp.76-85. 10.1021/acs.biomac.0c00374 . hal02618863

\section{HAL Id: hal-02618863 \\ https://hal.science/hal-02618863}

Submitted on 9 Jun 2020

HAL is a multi-disciplinary open access archive for the deposit and dissemination of scientific research documents, whether they are published or not. The documents may come from teaching and research institutions in France or abroad, or from public or private research centers.
L'archive ouverte pluridisciplinaire HAL, est destinée au dépôt et à la diffusion de documents scientifiques de niveau recherche, publiés ou non, émanant des établissements d'enseignement et de recherche français ou étrangers, des laboratoires publics ou privés. 


\title{
Design of thermoresponsive elastin-like
}

\section{glycopolypeptides for selective lectin binding and}

\section{sorting}

Lourdes Mónica Bravo Anaya, ${ }^{\dagger}$ Rosine Petitdemange, ${ }^{\dagger, \ddagger}$ Marie Rosselin, ${ }^{\dagger}$ Emmanuel

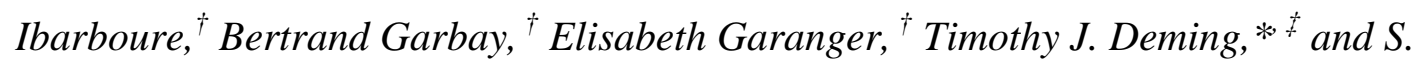
Lecommandoux ${ }^{* \dagger}$

${ }^{\dagger}$ Univ. Bordeaux, CNRS, Bordeaux INP, LCPO, UMR 5629, Pessac, F-33600, France.

${ }^{\ddagger}$ Department of Chemistry and Biochemistry, and Department of Bioengineering, University of California, Los Angeles, California 90095, United States.

\begin{abstract}
Selective lectin binding and sorting was achieved using thermosensitive glycoconjugates derived from recombinant elastin-like polypeptides (ELPs) in simple centrifugation-precipitation assays. A recombinant ELP, (VPGXG) ${ }_{40}$, containing periodically spaced methionine residues was used to enable chemoselective post-synthetic modification via thioether alkylation using alkyne functional epoxide derivatives. The resulting sulfonium groups were selectively demethylated to give alkyne functionalized homocysteine residues, which were then reacted with azidofunctionalized monosaccharides to obtain ELP glycoconjugates with periodic saccharide
\end{abstract}


functionality. These modifications were also found to allow modulation of ELP temperature dependent water solubility. The multivalent ELP glycoconjugates were evaluated for specific recognition, binding and separation of the lectin Ricinus communis agglutinin $\left(\mathrm{RCA}_{120}\right)$ from a complex protein mixture. $\mathrm{RCA}_{120}$ and ELP glycoconjugate interactions were evaluated using laser scanning confocal microscopy and dynamic light scattering. Due to the thermoresponsive nature of the ELP glycoconjugates, it was found that heating a mixture of galactosefunctionalized ELP and $\mathrm{RCA}_{120}$ in complex media selectively yielded a phase separated pellet of ELP-RCA 120 complexes. Based on these results, ELP glycoconjugates show promise as designer biopolymers for selective protein binding and sorting.

\section{KEYWORDS}

Elastin-like polypeptides (ELPs), saccharides, glycoconjugates, chemoselective postmodifications, click chemistry, lectins.

\section{INTRODUCTION}

Lectins are glycan-binding proteins that are widely distributed in nature and have diverse important functions on cells, such as agglutination, redistribution of cell surface components, toxicity, modification of the activity of membrane enzymes, cell aggregation, and immunomodulation. ${ }^{1-4}$ Lectins have recently been used to successfully detect cancer biomarkers in tissues and complex fluids. ${ }^{5}$ Many lectins have been applied in several medical research areas, such as drug delivery, ${ }^{6,7}$ inhibition of cancer cell adhesion, ${ }^{8}$ inhibition of cancer cell growth, ${ }^{9}$ and biomarkers for disease detection and monitoring, ${ }^{5}$ due to their carbohydrate binding specificities. Currently, cancer biomarker discovery is an important field of research, since only a few 
biomarkers are available for use in clinical settings. ${ }^{10}$ However, identifying the authentic biological ligand(s) for each lectin is still challenging. ${ }^{11-13}$ The development of new tools to identify lectin specificity and enable lectin discovery present new opportunities for understanding and using lectin functions. ${ }^{14}$

Related to these goals, C. R. Bertozzi, who was a pioneer in the development of glycopolymers for recognition of specific lectins, described the main applications of glycopolymers, ${ }^{15}$ namely, the enrichment of glycoproteins and glycopeptides from complex mixtures, the identification of protein glycosylation sites, for targeted glycoproteomics, and for functional glycoproteomics. All these areas are focused on identifying interactions between glycoproteins and glycan-binding proteins. ${ }^{15-18}$ In an important advance using well-defined glycopolymers and Concanavalin A as the model receptor, the group of D. M. Haddleton and C. R. Becer explored the influence of the nature and density of different sugar residues on the inhibitory potency of glycopolymers. ${ }^{19}$ The same group demonstrated that a simple glycopolymer can efficiently prevent the interactions between a human dendritic cell associated lectin (DC-SIGN) and the viral envelope glycoprotein gp120. ${ }^{20}$ This approach was expected to give rise to novel insights into the mechanisms of HIV infection and provide potential new therapeutics. Similarly, M. I. Gibson et al. developed complex glycopolymers bearing both primary glycan ligands and secondary units to modulate their selectivity toward lectins associated with specific diseases. ${ }^{21}$

Among glycopolymers, synthetic glycopolypeptides are particularly interesting candidates as glycoprotein analogs since their chemical structures give them the potential to closely mimick natural glycoprotein properties. ${ }^{22-25}$ Alternative synthetic routes such as solid-phase total synthesis of glycopeptides, ${ }^{26}$ native chemical ligations of glycopeptide fragments, ${ }^{26}$ and enzymatic synthesis of glycoproteins, ${ }^{27}$ have been explored and were successfully used to access 
fully synthetic glycoproteins. However, these chemical methods provide limited quantities of pure materials and generally require tedious and expensive syntheses. Overall, limitations of synthetic glycopolymers prevent the establishment of robust structure/activity relationships, either in terms of modest amounts and/or yields of biosynthesized glycoproteins obtained from biosynthetic methods, or in terms of sequence control (primary structure and chain length dispersity) for chemical polymerization methods.

Here, we sought to develop a robust method for producing thermosensitive glycopolypeptides of uniform length and precise carbohydrate spacing based on recombinant elastin-like polypeptides (ELPs) that are readily accessible at the gram scale. Specifically, we sought to utilize the temperature dependent solution properties of ELPs to control the interaction of multivalent galactose-functionalized ELPs with the lectin Ricinus communis agglutinin (RCA $\left.\mathrm{R}_{120}\right)$. Selective binding of these ELP glycoconjugates in complex human serum media was demonstrated through centrifugation/precipitation assays that allowed enrichment and separation of the complexes.

\section{MATERIALS AND METHODS}

\section{Materials}

Bacto-tryptone and yeast extract were obtained from Biokar Diagnostics (FR). LB medium was purchased from Sigma-Aldrich (FR). Ampicillin was purchased from Eurobio (FR). Glycerol and isopropyl $\beta$-D-thiogalactopyranoside (IPTG) were purchased from Euromedex (FR). Glycidyl propargyl ether was obtained from Sigma-Aldrich (Saint-Quentin-Fallavier, FR). Glacial acetic acid, Trizma ${ }^{\circledR}$ and Hexafluoroisopropanol (HFIP) were obtained from SigmaAldrich (FR). Deionized water (18 M $\Omega-\mathrm{cm})$ was obtained by using a Millipore Milli-Q Biocel 
A10 purification unit. Cuprisorb was purchased from Seachem. Ethanol (96.0\%, EtOH), methanol (98.5\%, $\mathrm{MeOH})$ and acetonitrile (99.9\%, ACN) were obtained from VWR international. $\mathrm{NaCl}(99 \%)$ was purchased from Alfa Aesar (FR). Azide monosaccharides ( $\beta$-Dgalactopyranosyl azide, Gal- $\mathrm{N}_{3}$; and $\beta$-D-glucopyranosyl azide $\left(\mathrm{Glu}-\mathrm{N}_{3}\right)$ were obtained from Carbosynth (UK). Ammonium Acetate and Ammonium pyrrolidinedithiocarbamate, APDC, were purchased from Fisher Scientific (FR). RCA 120 and RCA $_{120}$-Fluorescein were purchased from Eurobio (FR). Human serum from human male AB plasma, USA origin, sterile-filtered,

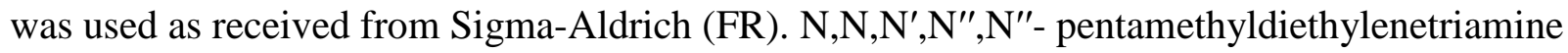
(PMDETA) was purchased from Sigma-Aldrich (FR). $\mathrm{CuSO}_{4} \cdot 5 \mathrm{H}_{2} \mathrm{O}$ was obtained from VWR (FR). Sodium ascorbate was obtained from Fisher Scientific (FR).

\section{Bioproduction of recombinant ELP}

ELP (MW[VPGVGVPGMG(VPGVG) $\left.{ }_{2}\right]_{10}$ ) was bio-produced, isolated and purified according to the procedures established by R. Petitdemange et al. ${ }^{28}$ ELP gene sequences and those of the corresponding protein were reported also by R. Petitdemange et al. ${ }^{28}$

\section{Synthetic procedures}

\section{Modification of ELP using epoxides ${ }^{29}$}

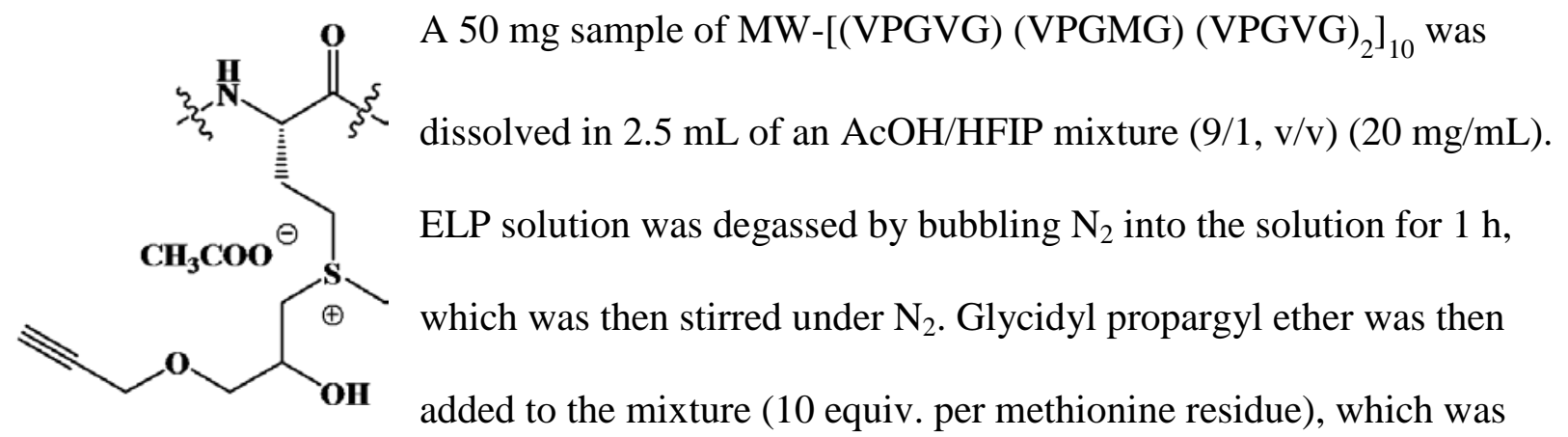


stirred for $48 \mathrm{~h}$ under $\mathrm{N}_{2}$ at room temperature. The obtained mixture was transferred into a 3000 MWCO centrifugal filter tube and washed with $40 \mathrm{~mL}$ DI water. The remaining content of the centrifugal filter tube was lyophilized to obtain the product ELP(Alkyne) as a white solid.

Details of ELP(Alkyne): ${ }^{1} \mathrm{H}$ NMR (400 MHz, $\left.\mathrm{D}_{2} \mathrm{O}, 25^{\circ} \mathrm{C}\right)$ : (main peaks) $\delta 4.5-4.4(\mathrm{~m}, 80 \mathrm{H}$, $\alpha \mathrm{CH} \underline{\mathrm{VPGXG}}$ and $\alpha \mathrm{CH}$ V $\underline{P G X G),} 4.3$ (s, $\left.22 \mathrm{H}, \underline{\mathrm{OCH}}_{2} \mathrm{CCH}\right), 4.2-4.15$ (d, 30 H, $\alpha \mathrm{CH}$ VPGG),

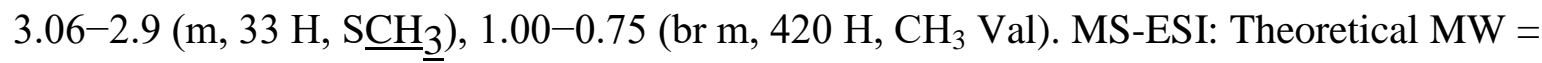
18279.1 Da, Experimental $\left[\mathrm{M}_{11}\right]^{11+}=1661.8$ Da. Yield=97 \%.

\section{Demethylation of ELP(Alkyne $)^{29}$}

A $50 \mathrm{mg}$ sample of ELP(Alkyne) was dissolved in 75\% EtOH (aq) at a $10 \mathrm{mM}$ concentration and then treated with ammonium pyrrolidinedithiocarbamate, APDC, (5.0 equiv per methionine residue). The solution was rapidly flushed with a stream of $\mathrm{N}_{2}$ and rapidly capped. The reaction mixture was vortexed until obtaining a homogeneous solution, which was then allowed to stand for $24 \mathrm{~h}$ at room temperature. The obtained mixture was transferred to a $1 \mathrm{kDa}$ MWCO dialysis bag and dialyzed against 50\% $\mathrm{MeOH}(\mathrm{aq})$ during $24 \mathrm{~h}$ with 3 solvent changes followed by $8 \mathrm{~h}$ dialysis against DI water with 3 changes. The dialysis bag contents were then lyophilized to provide the product ELP(Dem Alkyne).

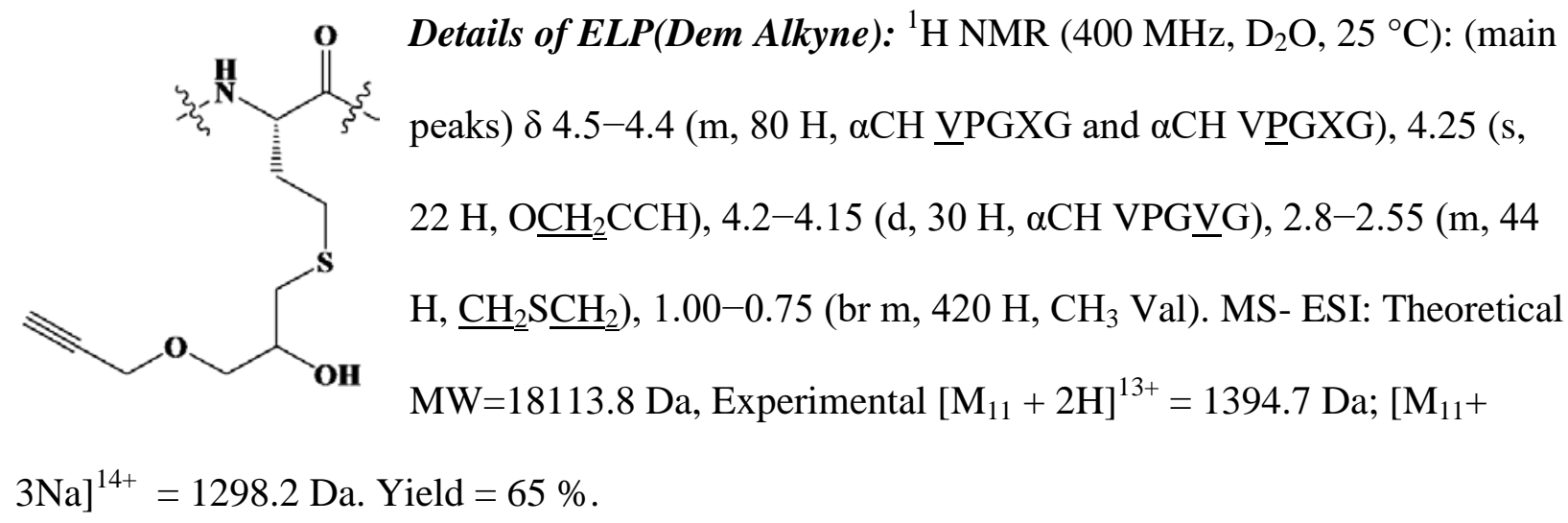




\section{Synthesis of ELP glycoconjugates.}

A sample of ELP(Dem Alkyne) was dissolved in water $(5 \mathrm{mg} / \mathrm{mL})$ and the desired azidofunctionalized monosaccharide, either $\beta$-D-galactopyranosyl azide or $\beta$-D-glucopyranosyl azide (powder, 1.5 equiv. per alkyne) was added. The solution was degassed by bubbling $\mathrm{N}_{2}$ for 2 hrs and then stirred under $\mathrm{N}_{2}$. Separately, a solution of $\mathrm{Cu}(\mathrm{I})$ was prepared by addition of sodium ascorbate (0.65 equiv. per alkyne) to a degassed solution of $\mathrm{Cu}(\mathrm{II}) \mathrm{SO} 4$ (0.13 equiv. per alkyne) and pentamethyldiethylenetriamine ( 0.13 equiv. per alkyne). The $\mathrm{Cu}(\mathrm{I})$ solution then was transferred to the reaction mixture with a syringe. The reaction was stirred under $\mathrm{N}_{2}$ at room temperature for 72 hrs. Cuprisorb (100 mg), a powerful absorbent of copper, ${ }^{30}$ was added to the reaction mixture and stirred overnight. Cuprisorb beads were separated by centrifugation and the supernatant was transferred to a 3000 MWCO centrifugal filter tube, which was washed first with an aqueous solution of EDTA (0.15 M) and then with $40 \mathrm{~mL}$ DI water. The purified reaction mixture was then lyophilized to provide the ELP glycoconjugate as a white solid.

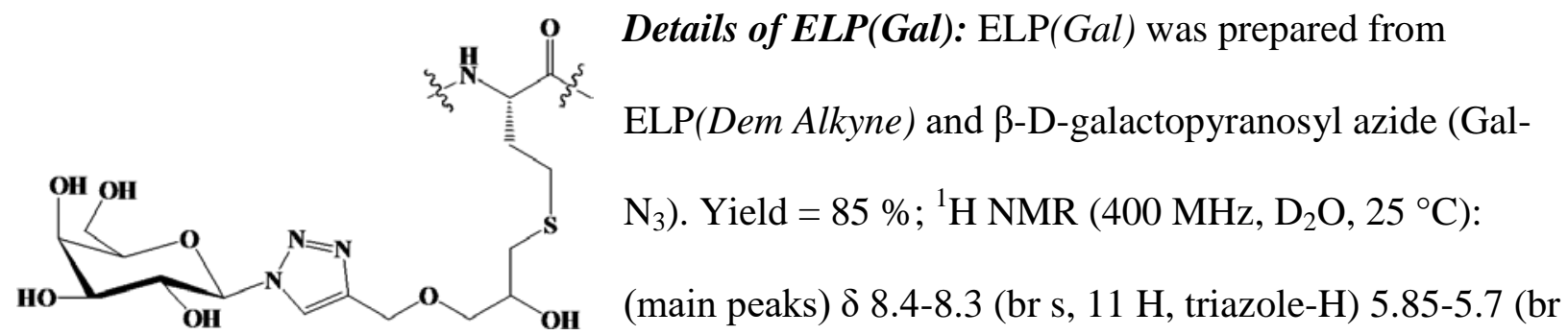

s, $11 \mathrm{H}$, anomeric-H), 4.5-4.4 (m, 80 H, $\alpha \mathrm{CH} \underline{\mathrm{V} P G X G}$ and $\alpha \mathrm{CH}$ VPGXG), 4.2-4.15 (d, $30 \mathrm{H}$, aCH VPG్), 1.00-0.75 (br m, 420 H, $\mathrm{CH}_{3}$ Val). Theoretical MW = 20369.7 Da.

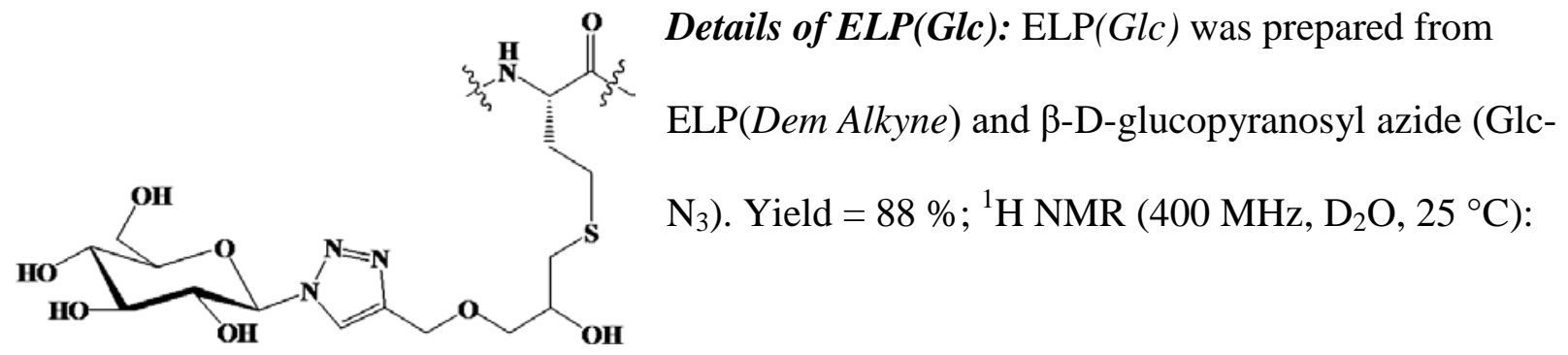


(main peaks): $\delta$ 8.4-8.3 (br s, $11 \mathrm{H}$, triazole-H) 5.9-5.75 (br s, $11 \mathrm{H}$, anomeric-H), 4.5-4.4 (m, 80

$\mathrm{H}, \alpha \mathrm{CH} \underline{\mathrm{V} P G X G}$ and $\alpha \mathrm{CH}$ V $\underline{P G X G)}$, 4.2-4.15 (d, $30 \mathrm{H}, \alpha \mathrm{CH}$ VPGG), 2.7 ppm (s, $9 \mathrm{H}, \mathrm{CH}_{3}$ Met-ox) 1.00-0.75 (br m, 420 H, $\mathrm{CH}_{3}$ Val). Theoretical MW = 20 369.7 Da.

\section{${ }^{1}$ H NMR analyses}

${ }^{1} \mathrm{H}$ NMR analyses were performed on a Bruker AVANCE III HD 400 apparatus equipped with a $5 \mathrm{~mm}$ Bruker multinuclear z-gradient direct probe operating at $400.2 \mathrm{MHz}$ for ${ }^{1} \mathrm{H}$ and 100.6 $\mathrm{MHz}$ for ${ }^{13} \mathrm{C}$. An amount of $7 \mathrm{mg}$ of material was dissolved in $0.5 \mathrm{~mL}$ of deuterated solvent $\left(\mathrm{D}_{2} \mathrm{O}\right)$ and 128 scans were recorded for ${ }^{1} \mathrm{H}$ experiments. ${ }^{1} \mathrm{H}$ NMR spectra were acquired in $\mathrm{D}_{2} \mathrm{O}$ at $25^{\circ} \mathrm{C}$. The solvent signal was used as the reference signal $(\delta=4.79 \mathrm{ppm})$. HSQC analyses were performed on a Bruker AVANCE NEO 400 spectrometer operating at $100.7 \mathrm{MHz}$, equipped with a $5 \mathrm{~mm}$ Bruker multinuclear z-gradient direct cryoprobe-head operating at $25^{\circ} \mathrm{C}$. Data processing was performed using Bruker Topspin Software. Chemical shifts of amino acids are well-known in the literature. ${ }^{31,32}$

\section{Size Exclusion Chromatography (SEC) analyses}

SEC analyses of ELP derivatives were performed on a liquid chromatographic system from ThermoScientific equipped with two G4000PWXL and G3000PWXL gel columns (300 x 7.8 mm) (exclusion limits from $200 \mathrm{Da}$ to $300000 \mathrm{Da}$ ) and UV detector at a flow rate of 0.6 $\mathrm{mL} / \mathrm{min}$. Column temperatures were held at $25{ }^{\circ} \mathrm{C}$. The system includes a multi-angle light scattering detector MALS and differential refractive index detector dRI from Wyatt technology. Aqueous solvent composed of acetic acid (AcOH) $0.3 \mathrm{M}$, ammonium acetate $0.2 \mathrm{M}$ and ACN (6.5/3.5, v/v) was used as the eluent. Ethylene glycol was used as flow marker. 


\section{Transition temperature $\left(T_{t}\right)$ measurements of ELP derivatives}

Dynamic light scattering (DLS) measurements were performed on a Malvern ZetaSizer Nano ZS instrument equipped with a standard HeNe laser emitting at $632.8 \mathrm{~nm}$ (Malvern, U.K.) at a $90^{\circ}$ angle at a constant position in the cuvette (constant scattering volume). An amount of $100 \mu \mathrm{L}$ of sample was introduced in a high precision cell with a light path of 3x3 mm made of quartz. Solutions of ELP, ELP(Alkyne), ELP(Dem Alkyne), ELP(Gal) and ELP(Glc), were prepared at a range of concentrations between 0.1 and $2.0 \mathrm{mM}$ in Trizma buffer (50 mM Trizma, $0.15 \mathrm{M}$ $\mathrm{NaCl})$. The selected buffer allowed conserving a constant $\mathrm{pH}$ (7.5), which was selected to perform carbohydrate-lectin binding experiments in the appropriate conditions to maintain RCA $_{120}$ conformation and properties. ${ }^{33}$ One measurement of four runs (10 s each one) was recorded during a temperature ramp programmed from 15 to $74{ }^{\circ} \mathrm{C}$ every 1.8 degrees after a 2 min-temperature equilibration time. The derived count rate (DCR) was defined as the mean scattered intensity normalized by the attenuation factor. The derived count rate was plotted against temperature and the transition temperature $\left(T_{t}\right)$ was determined by taking the onset of aggregation of the ELP, corresponding to the point where the scattered intensity starts increasing on this plot. $^{29}$

\section{Dynamic light scattering (DLS) measurements}

Dynamic light scattering measurements were performed on a Malvern ZetaSizer Nano ZS instrument equipped with a standard HeNe laser emitting at $632.8 \mathrm{~nm}$ (Malvern, U.K.) at a 90 angle. An amount of $100 \mu \mathrm{L}$ of sample was introduced in a high precision cell with a light path of 3x3 mm made of quartz. The correlation functions were averaged from three measurements of 10 runs (30 s each one) at a temperature of $25^{\circ} \mathrm{C}$ after a 2 min-temperature equilibration time. 


\section{Laser Scanning Confocal Microscopy (LSCM)}

Laser Scanning Confocal Microscopy images were acquired on an inverted Leica TCS SP5 microscope equipped with an HCX PL APO 63X, NA 1.4 oil immersion objective in fluorescence mode. The laser outputs were controlled via the Acousto-Optical Tunable Filter (AOTF) and the two collection windows using the Acousto-Optical Beam Splitter (AOBS) and photomultiplier tubes (PMT) as follows: Fluorescein was excited with an argon laser at $488 \mathrm{~nm}$ (12\%) and measured with emission settings at 500-550 nm. The helium-neon laser at $633 \mathrm{~nm}$ (10\%) was only used in transmission mode. Images were collected using the microscope in sequential mode with a line average of 8 and a format of $512 * 512$ pixels or $1024 * 1024$ pixels. Samples $(\approx 30 \mu \mathrm{L})$ were injected in $\mu$-slide (chambered coverslip) with uncoated 8 wells from Ibidi GmbH. Processing of fluorescence confocal acquisitions were performed with the ImageJ freeware.

\section{Centrifugation/precipitation assays}

Solutions of ELP(Gal) or ELP(Glc) at a concentration of $200 \mu \mathrm{M}$ were mixed with RCAFluorescein $(31.2 \mu \mathrm{M})$ in Trizma buffer to prepare samples for centrifugation/precipitation assays. After mixture, solutions were incubated under shaking at room temperature for 20 min to allow the carbohydrate-RCA $\mathrm{A}_{120}$ interaction to take place. ${ }^{34}$ Then, temperature was increased to 37 ${ }^{\circ} \mathrm{C}$ and samples were incubated for $20 \mathrm{~min}$. Finally, solutions were centrifuged at $40{ }^{\circ} \mathrm{C}$ for 20 minutes at 10,000 g. Supernatant was removed and the pellet was re-suspended in fresh buffer. An UV-Vis lamp at $365 \mathrm{~nm}$ was used to illuminate samples to identify presence of the fluorescence signal. 


\section{RESULTS AND DISCUSSION}

ELPs derived from the hydrophobic domain of tropoelastin consist of repeated pentapeptide sequences of [-Val-Pro-Gly-Xaa-Gly-], with the residue Xaa being any amino acid except proline. $^{28,29,35}$ An interesting property of ELPs comes from their lower critical solution temperature (LCST) phase behavior. When ELPs are dissolved in aqueous media, they hydrophobically collapse above a critical temperature, named $\mathrm{T}_{\mathrm{t}}$, into insoluble aggregates forming a coacervate phase. ${ }^{36,37}$ This temperature can be precisely tuned by modifying the initial design of the ELP, namely the amino acid composition and the ELP chain length, ${ }^{38-40}$ or by subsequent chemical modification of the ELP backbone. ${ }^{22,23}$ Post-synthesis modifications of ELPs reported in the literature often target their chain ends to graft small organic molecules, ${ }^{41}$ oligonucleotides, ${ }^{42}$ drugs $^{43}$ or PEG chains. ${ }^{44}$ Modifications at the amino acid side chains within the ELP domain have recently been explored generating a wide variety of chemical functionalizations. ${ }^{28,29,45,46}$ Recently, our group reported a method that allows chemical postsynthesis modifications by oxidation or alkylation of selectively introduced methionine residues, allowing both the modulation of $\mathrm{T}_{\mathrm{t}}$ as well as the introduction of functional groups. ${ }^{28,47}$ This method has improved the versatility of ELP post-synthesis modifications to introduce new functionalities, and modified the ELPs properties such as the thermoresponsiveness. However, up to now, ELPs have not been used to prepare glycopolypeptides, which has become an attractive field of research for a wide range of applications, such as the development of biosensors or bio-responsive drug carriers.

This study is focused on the design and synthesis of thermoresponsive ELP glycoconjugates for selective lectin binding and sorting, featuring galactose (Gal) units grafted onto the methionine 
side chains of ELP[M $\left.\mathrm{M}_{1} \mathrm{~V}_{3}-40\right]$ corresponding to the sequence (VPGXG) ${ }_{40}$, where X=V/M (3:1), here simply referred to as ELP (Scheme 1a). ${ }^{29}$ This ELP was chemoselectively modified so that the $\mathrm{T}_{\mathrm{t}}$ at certain concentrations was lower than $40^{\circ} \mathrm{C}$, a temperature at which some proteins start to denature irreversibly and hence critical for temperature dependent sorting of proteins bound to the ELP. All 11 methionine residues of the ELP were chemoselectively alkylated using glycidyl propargyl ether, an alkyne-containing epoxide derivative (Scheme $\mathbf{1 b}){ }^{28}$ Because the resulting ELP sulfonium derivative, ELP(Alkyne), is too hydrophilic to possess a $\mathrm{T}_{\mathrm{t}}$ in the desirable range $\left(<40^{\circ} \mathrm{C}\right)$, the latter was subsequently demethylated (using ammonium pyrrolidinedithiocarbamate, APDC, in 75\% ethanol), to give ELP(Dem Alkyne) with appropriate $\mathrm{T}_{\mathrm{t}}$. ELP(Dem Alkyne) was then reacted with different azido-functionalized monosaccharides, i.e. galactose and glucose, via copper-catalyzed azide-alkyne cycloaddition (CuAAC). ${ }^{48,49}$ The reaction conditions used $\left(\mathrm{H}_{2} \mathrm{O}, \mathrm{Cu}(\mathrm{II}) \mathrm{SO}_{4}\right.$, sodium ascorbate, PMDETA) were similar to those described by Deming et al. for the modification of alkyne-functionalized statistical copolymers of Met and Lys. ${ }^{50}$ Compared to synthetic polypeptides, a longer reaction time of 72 hrs and excess monosaccharide, i.e. 1.5 equiv. azido-sugar per Met residue, was necessary to achieve quantitative functionalization of the ELP. ${ }^{51}$ 


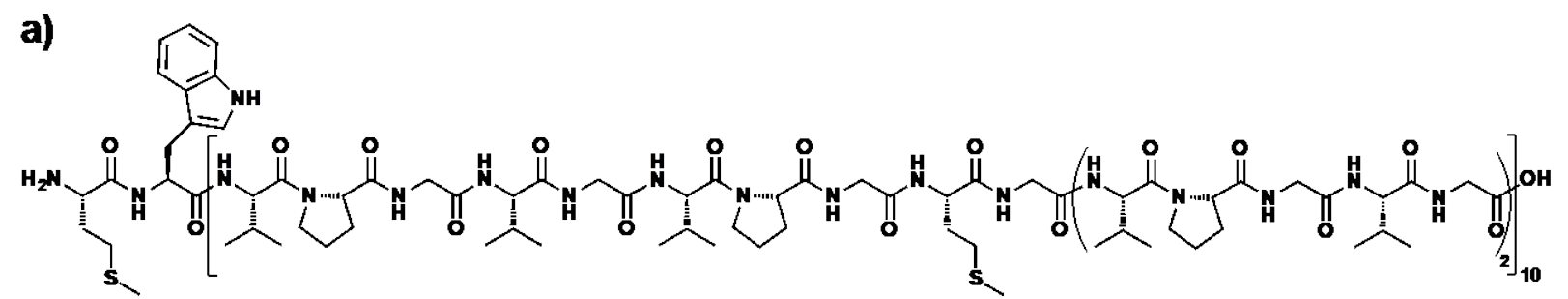

b)

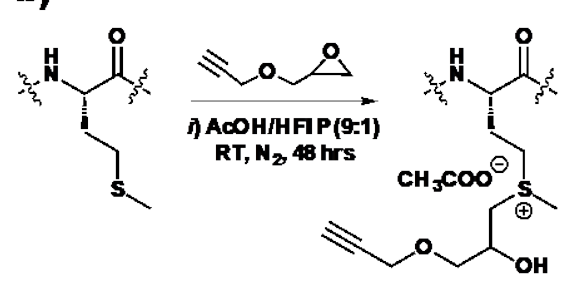

ELP

ELP(Alkyne)

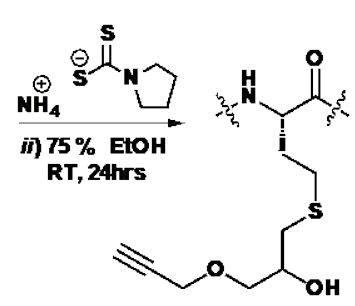

ELP(Dem Alkyne)

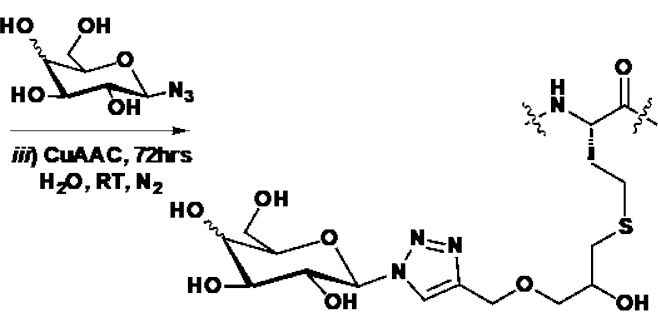

ELP(Ga)

ELP(GC)

Scheme 1. a) Amino acid sequence of ELP, b) Three step reaction scheme to access ELP(Gal) and $\operatorname{ELP}($ Glc): i) alkylation of ELP with glycidyl propargyl ether to introduce alkyne functionality and yield ELP(Alkyne), ii) demethylation of ELP(Alkyne) to give ELP(Dem Alkyne), and iii) click chemistry with Gal- $\mathrm{N}_{3}$ or Glc- $\mathrm{N}_{3}$ to give $\operatorname{ELP}(\mathrm{Gal})$ or $\operatorname{ELP}(G l c)$, respectively.

The degree of functionalization of ELP(Alkyne) after alkylation at the thioether groups was determined by ${ }^{1} \mathrm{H}$ NMR spectroscopy as described previously (Figure 1a and b). ${ }^{29}{ }^{1} \mathrm{H}$ NMR spectra were calibrated using the resonances centered at $4.45 \mathrm{ppm}$, which correspond to the $\alpha \mathrm{CH}$ protons of the first valine in each (VPGXG) repeat and to the $\alpha \mathrm{CH}$ protons of proline, integrating as 80 total protons (Figures S1 and S2). Integration of the resonance at ca. 3 ppm, corresponding to the Met sulfonium methyl group of ELP(Alkyne) was used to determine the extent of ELP alkylation (full functionalization corresponds to 33 protons for 11 Met sulfonium groups). A degree of functionalization around $92 \pm 2 \%$ ( $n=10$ ) was obtained for the synthesized ELP(Alkyne) at this step. A small amount of Met sulfoxide was detected in ELP(Alkyne) during the reaction (less than 10\%), as evidenced by the appearance of resonances at $2.7 \mathrm{ppm}$, 
corresponding to $-\mathrm{S}(\mathrm{O}) \mathrm{CH}_{3}$ protons. Other resonances, such as the singlet at $4.3 \mathrm{ppm}$, corresponding to the methylene group in $\alpha$ position to the alkyne function and integrating as 22 protons, were also used to confirm degree of alkylation (Figures S2 and S3). Demethylation of methionine sulfoniums, leading to a less hydrophilic ELP derivative, ELP(Dem Alkyne), was also evaluated by ${ }^{1} \mathrm{H}$ and ${ }^{13} \mathrm{C}$ NMR spectroscopy (Figures 1c, S4, S5 and S6). ELP(Alkyne) was found to be efficiently demethylated to give the corresponding S-alkyl-L-homocysteine residues as confirmed by ${ }^{1} \mathrm{H}$ NMR analysis (Figure 1c). Subsequently, complete functionalization with monosaccharides after click chemistry was assessed by ${ }^{1} \mathrm{H}$ NMR spectroscopy. The resonance signal of the methylene group in $\alpha$ position to the alkyne group shifted downfield (from $4.3 \mathrm{ppm}$ to $4.7 \mathrm{ppm}$ ) due to the modification of the chemical environment. Simultaneous appearance of the resonances at $8.2 \mathrm{ppm}$ and at $6.18 \mathrm{ppm}$ is attributed to the proton of the triazole ring and to the anomeric proton of the monosaccharide, respectively (Figures 1d, S7, S8 and S9). After click chemistry, functionalization degrees for each glycopolypeptide were found to be $93 \pm 2 \%$ for $\operatorname{ELP}(\mathrm{Gal})$ and $80 \pm 3 \%$ for $\operatorname{ELP}($ Glc). The molecular weight changes of each ELP derivative after the chemical modifications were followed by SEC analyses in aqueous solvent (acetic acid 0.3 M, ammonium acetate $0.2 \mathrm{M} / \mathrm{ACN} ; 6.5 / 3.5$, v/v). SEC traces showed expected shifts for each ELP derivatives (Figure S11). SEC also evidenced the presence of a small amount of dimer species (less than $10 \%$ ), the origin of which is not fully understood but considered negligible for the purpose of this work. 


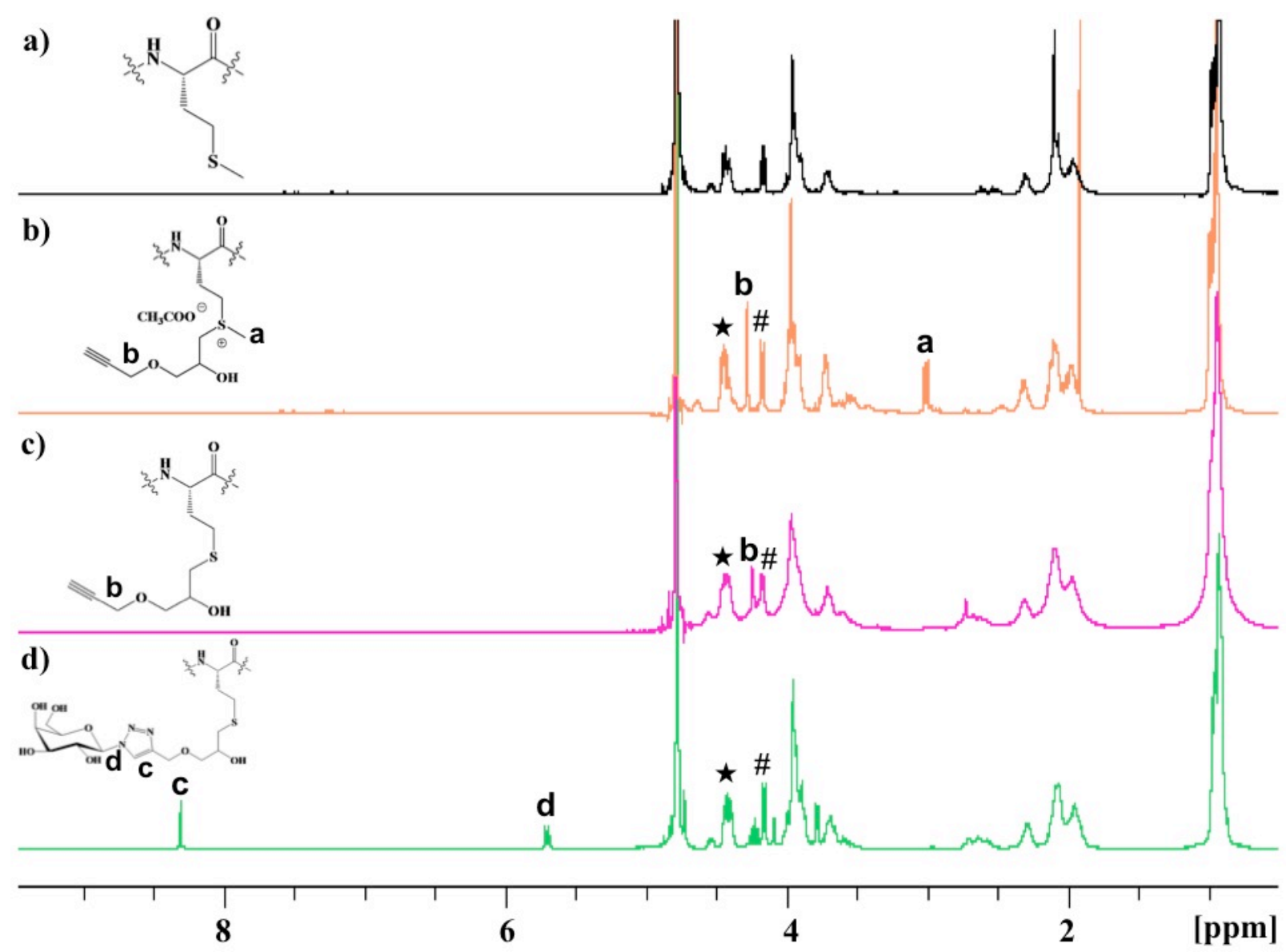

Figure 1. ${ }^{1} \mathrm{H}$ NMR spectra of a) ELP, b) ELP(Alkyne), c) ELP(Dem Alkyne) and d) ELP(Gal) in $\mathrm{D}_{2} \mathrm{O}$ at $25^{\circ} \mathrm{C}$. Resonance \# corresponds to $\mathrm{Val} \alpha \mathrm{CH}$ of the guest residue in VPGG repeat units, and resonance $\star$ corresponds to $\mathrm{Val} \alpha \mathrm{CH}$ and Pro $\alpha \mathrm{CH}$ of $\underline{\mathrm{VPGXG}}$ repeats.

Considering the strong effect of chemical modifications of Met-containing ELPs on their thermoresponsive properties, ${ }^{28,29,51,52}$ the temperature-induced aggregation of all ELP derivatives and glycoconjugates described above was evaluated by dynamic light scattering (DLS) at a $90^{\circ}$ angle over a wide range of concentrations (Figure S12). Figure 2a shows the scattered light intensity as a function of temperature for the different ELP derivatives and glycoconjugates (at a concentration of $200 \mu \mathrm{M}$ ), which was measured and plotted versus increasing temperature from 
$15{ }^{\circ} \mathrm{C}$ to $74{ }^{\circ} \mathrm{C}$. This allowed the determination of the onset temperature of aggregation $\left(\mathrm{T}_{\mathrm{t}}\right)$. As expected at such concentration, ELP(Alkyne) did not present any aggregation in the range of temperatures studied, whereas the pristine ELP did $\left(\mathrm{T}_{\mathrm{t}}=26^{\circ} \mathrm{C}\right) .{ }^{29}$ This lack of aggregation was readily attributed to the increased hydrophilicity of the thioalkylated ELP resulting mainly from the positively charged sulfonium groups. This hypothesis was confirmed after demethylation, since the $\mathrm{T}_{\mathrm{t}}$ of $\operatorname{ELP}\left(\right.$ Dem Alkyne) was found around $23^{\circ} \mathrm{C}$, showing that the removal of the multiple positively charged sulfonium groups restored the thermoresponsive properties. ${ }^{53}$ Glycopolypeptides, i.e. ELP(Gal) and ELP(Glc), showed very similar thermoresponsive behavior, presenting $\mathrm{T}_{\mathrm{t}}$ values of ca. $36^{\circ} \mathrm{C}$ and $38{ }^{\circ} \mathrm{C}$, respectively, at the selected concentration (Table S1). At higher temperatures, as well as at higher concentrations (Figure S11), a decrease of the scattered intensity was observed due to ELPs precipitation. The increase in $T_{t}$ observed after ELP glycosylation was expected due to the contributions of the polar hydroxyl groups from the monosaccharides. As shown by Miyajima et al. ${ }^{54}$ the relative hydrophobic/hydrophilic character of saccharides however depends on multiple parameters (i.e. dimension of hydrophobic/hydrophilic surface area, conformation, hydrogen bonding, etc.) and depending on which parameter is taken into account in the calculation of the hydrophobicity index, the ranking of individual saccharides is subject to variation. Finally, for all samples, except ELP(Alkyne), $\mathrm{T}_{\mathrm{t}}$ versus concentration was plotted and used to determine accurate estimates of the $T_{t}$ values for a given concentration (Figure 2b). 
a)

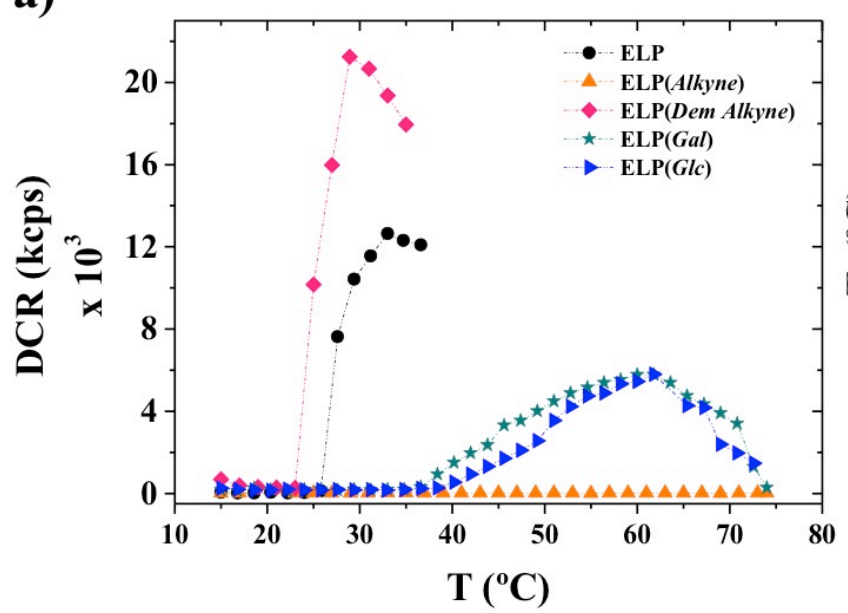

b)

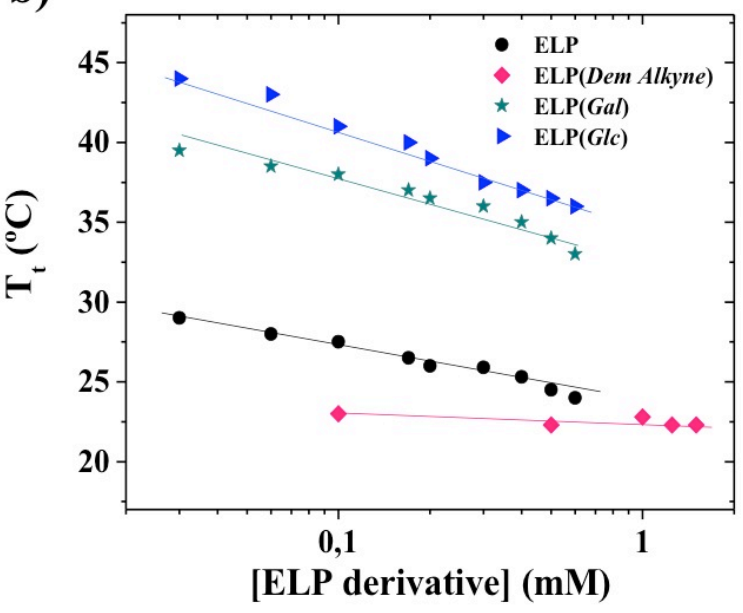

Figure 2. a) Scattered light intensity of ELP derivatives, i.e. ELP, ELP(Alkyne), ELP(Dem Alkyne), $\operatorname{ELP}(\mathrm{Gal})$ and $\operatorname{ELP}(\mathrm{Glc})$ as a function of temperature at $200 \mu \mathrm{M}$ in Trizma buffer (50 mM Trizma, 0.15 M NaCl), b) $\mathrm{T}_{\mathrm{t}}$ values of ELP (black circles), ELP(Dem Alkyne) (pink diamonds), ELP(Gal) (green stars) and ELP(Glc) (blue triangles) as function of molar concentration.

Dynamic light scattering experiments were then used to determine the binding capacity of $\operatorname{ELP}(G a l)$ and $\operatorname{ELP}(G l c)$ to a specific lectin, namely $\mathrm{RCA}_{120}$, by monitoring aggregation behavior as depicted by the evolution of the correlation functions of the different species individually or in mixtures. The correlation function measured by DLS is a direct measurement of characteristic time $(\tau)$ of objects in solution, related to their Brownian motion: lower $\tau$ corresponds to smaller objects/colloids in solution. ${ }^{55}$ Figure 3a shows that the correlation function for RCA $_{120}$ corresponds to that of small individual colloidal particles, ${ }^{56}$ while glycosylated ELPs, either with galactose or with glucose, present nearly the same correlation function with longer decay times 
due to their larger colloidal size. The addition of RCA 120 into a solution containing ELP(Gal), at a ratio of 35 sugars per $\mathrm{RCA}_{120}$ active site (determined by taking into account 10 sugars per ELP and 2 active sites per $\mathrm{RCA}_{120}$ ), showed a correlation function depicting strong aggregation of ELP(Gal), as a consequence of its binding with RCA120. ${ }^{57}$ This kind of aggregation phenomena has also been observed through kinetic studies of light absorbance for complexes of glycopeptide polymersomes formed from galactose bearing $\mathrm{PBLG}_{20}-b-\mathrm{PGG}_{25}$ copolymers with $\mathrm{RCA}_{120} \cdot{ }^{34} \mathrm{On}$ the other hand, no hallmark of aggregation was observed when ELP(Glc) was used in a similar experiment. $\mathrm{ELP}(G l c)$ was chosen as a negative control because D-glucose is not supposed to bind to RCA $_{120}{ }^{57}$ Figure $3 \mathbf{b}$ shows the evolution of correlation functions of RCA 120 solutions at the same concentration (31.2 $\mu \mathrm{M})$ after the addition of increasing amounts of ELP(Gal). Interaction and aggregation of $\operatorname{ELP}(\mathrm{Gal})$ with $\mathrm{RCA}_{120}$ was detected as soon as $2 \mu \mathrm{M}$ of ELP(Gal) were added to the RCA $\mathrm{R}_{120}$ solution, corresponding to approximately $3 \mathrm{RCA}_{120}$ active sites per sugar unit. This technique was also used by Ma et al. to show the interactions between $\mathrm{RCA}_{120}$ and glycopolymers bearing galactose and betulin. They also observed the increase in size of the aggregates with time upon the addition of the lectin, which was explained by a possible intermicellar cross-linking due to the two identical binding sites of the $\mathrm{RCA}_{120} \cdot{ }^{58}$ 
a)

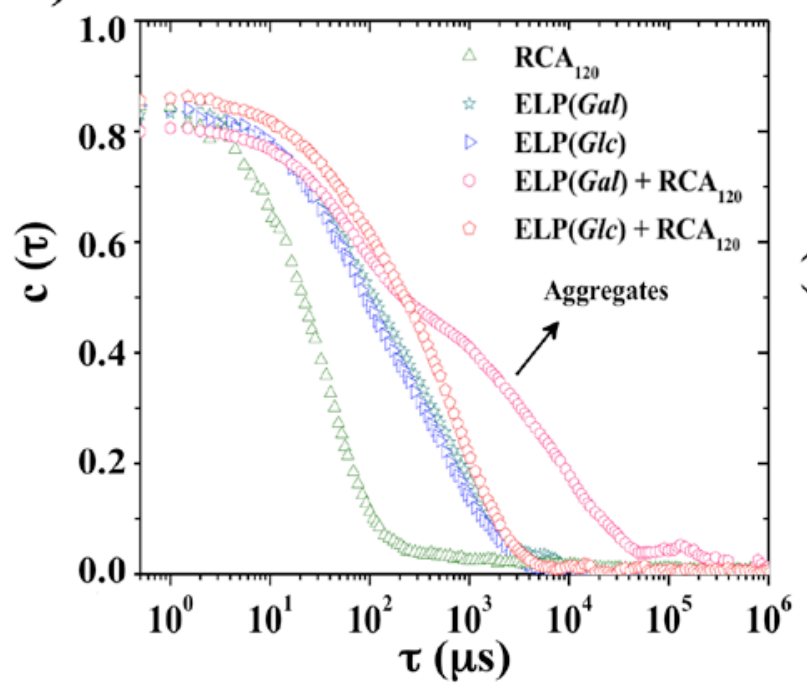

b)

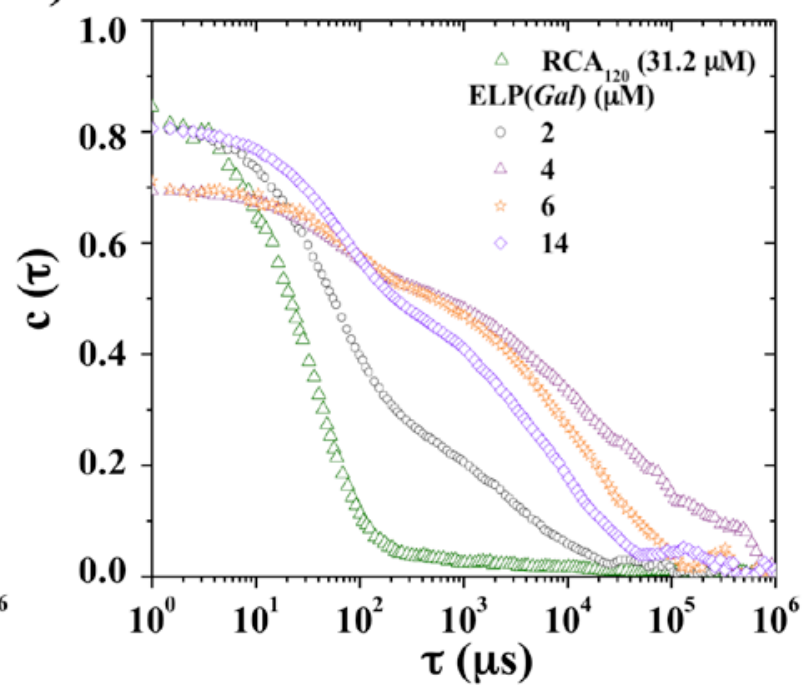

Figure 3. a) Correlation functions of $31.2 \mu \mathrm{M}_{\text {RCA }}{ }_{120}, 200 \mu \mathrm{M} \operatorname{ELP}(G a l), 200 \mu \mathrm{M} \mathrm{ELP(Glc),}$ $31.2 \mu \mathrm{M} \mathrm{RCA}_{120} / 200 \mu \mathrm{M} \operatorname{ELP}\left(\right.$ Gal) and $31.2 \mu \mathrm{M} \mathrm{RCA}_{120} / 200 \mu \mathrm{M} \mathrm{ELP}\left(\right.$ Glc) at $25^{\circ} \mathrm{C}$, b) Evolution of $\mathrm{RCA}_{120}(31.2 \mu \mathrm{M})$ correlation function during progressive addition of ELP(Gal) at $25{ }^{\circ} \mathrm{C}$.

After demonstrating the selective binding of $\operatorname{ELP}(\mathrm{Gal})$ to $\mathrm{RCA}_{120}$ lectin, we sought to take advantage of the thermoresponsive behavior of ELPs which form coacervates above $T_{t}$, to help precipitate the $\operatorname{ELP}(\mathrm{Gal}) / \mathrm{RCA}_{120}$ complexes, and thus achieve sorting and recovery of the lectin from complex media. The specific binding of $\operatorname{ELP}(\mathrm{Gal})$ to $\mathrm{RCA}_{120}$ in buffer and in serum containing medium was then assayed in temperature-triggered aggregation-centrifugation experiments (Figure 4). In these experiments, ELP(Gal) or ELP(Glc) $(200 \mu \mathrm{M})$ were incubated above $\mathrm{T}_{\mathrm{t}}$ at $37^{\circ} \mathrm{C}$ with fluorescently labeled $\mathrm{RCA}_{120}(31.2 \mu \mathrm{M})$ and the mixture was subjected to centrifugation at $40^{\circ} \mathrm{C}$. With $\operatorname{ELP}(\mathrm{Gal})$, a distinct pellet was separated from the supernatant, as 
observed under light and fluorescence microscopy (Figure 4a and 4b, Figure S13). When the negative control ELP(Glc) was used, no detectable fluorescent pellet was recovered (Figure 4a and $4 \mathbf{b}$, Figure S13) and soluble $\mathrm{RCA}_{120}$-fluorescein was recovered in the supernatant. In contrast, when $\mathrm{RCA}_{120}$-fluorescein was incubated with $\operatorname{ELP}(\mathrm{Gal})$ above $\mathrm{T}_{\mathrm{t}}$, only a very weak fluorescence signal was measured in the supernatant. This can readily be explained by the specific binding of $\mathrm{RCA}_{120}$ to $\operatorname{ELP}(\mathrm{Gal})$ derivative and the temperature-induced aggregation of the $\mathrm{RCA}_{120} / \mathrm{ELP}(\mathrm{Gal})$ complex upon heating at $40{ }^{\circ} \mathrm{C}$. This was confirmed by the strong fluorescence signal recovered after re-suspension of the $\mathrm{RCA}_{120} / \mathrm{ELP}(\mathrm{Gal})$ pellet in cold buffer, below the $\mathrm{T}_{\mathrm{t}}$ of $\operatorname{ELP}(\mathrm{Gal})$ (Figure S13d). Similar results were obtained when serum was added to the medium (Figures $\mathbf{4 c}$ and $\mathbf{4 d}$ ).

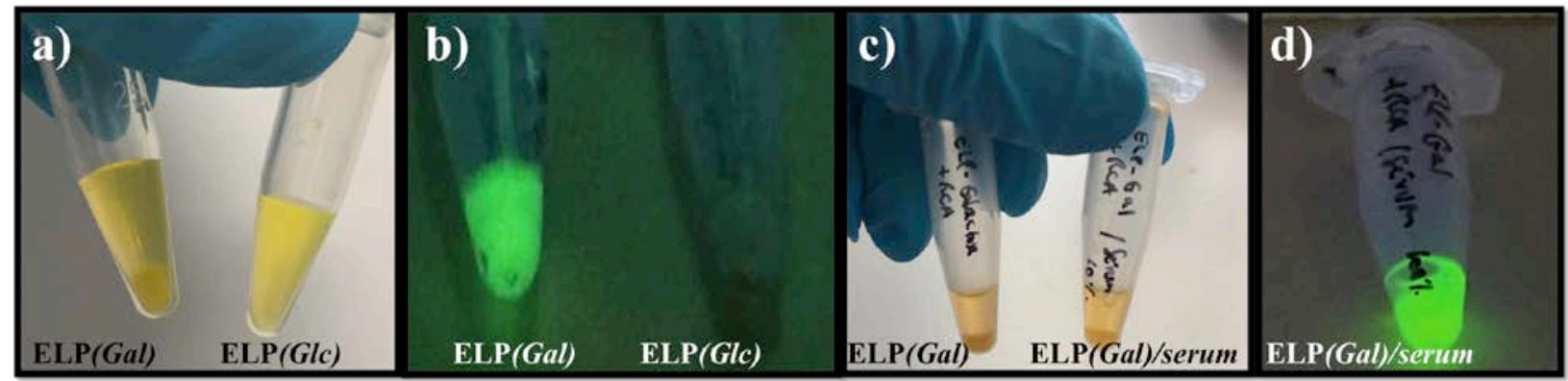

Figure 4. a) $31.2 \mu \mathrm{M} \mathrm{RCA}_{120}$-Fluorescein incubated at $37^{\circ} \mathrm{C}$ with either $200 \mu \mathrm{M}$ ELP(Gal) (left) or $200 \mu \mathrm{M} \operatorname{ELP}(G l c)$ (right), b) Samples from panel a) were subjected to centrifugation at $40{ }^{\circ} \mathrm{C}$. After supernatant removal, any pellet was re-suspended in cold buffer and the resulting solution illuminated under UV light at $365 \mathrm{~nm}$, c) $31.2 \mu \mathrm{M} \mathrm{RCA}_{120}$-Fluorescein incubated at 37 ${ }^{\circ} \mathrm{C}$ with either $200 \mu \mathrm{M}$ ELP(Gal) (left) or $200 \mu \mathrm{M}$ ELP(Gal) in the presence of serum (right), d) $31.2 \mu \mathrm{M}$ RCA 120 -Fluorescein incubated at $37^{\circ} \mathrm{C}$ with $200 \mu \mathrm{M}$ ELP(Gal) in the presence of 
serum, then subjected to centrifugation at $40^{\circ} \mathrm{C}$. After supernatant removal, the pellet was resuspended in cold buffer and the resulting solution illuminated under UV light at $365 \mathrm{~nm}$.

Fluorescence microscopy measurements were also performed to visualize the interactions between ELP glycoconjugates and lectins. Samples containing either $31.2 \mu \mathrm{M} \mathrm{RCA}_{120^{-}}$ Fluorescein or $31.2 \mu \mathrm{M}$ RCA $_{120}$-Fluorescein/200 $\mu \mathrm{M}$ ELP(Glc) were used as negative controls (Figures 5a and 5c). No microscopic aggregate structure formation was observed, suggesting that $\mathrm{RCA}_{120}$ maintains its solubility and conformation (it is known to denature above $52{ }^{\circ} \mathrm{C}$ ) and that $\mathrm{RCA}_{120}$-Fluorescein/ELP(Glc) do not bind to each other (Figure S13). Interestingly, structures formed at $37^{\circ} \mathrm{C}$ in the mixture containing $31.2 \mu \mathrm{M} \mathrm{RCA}_{120}$-Fluorescein and $200 \mu \mathrm{M}$ ELP(Gal) (Figure 5b), appear similar to disordered fractal aggregates. ${ }^{59,60}$ Such structures have been recently reported by Roberts et al. ${ }^{61}$ for thermally responsive partially ordered polypeptides that combine the stimuli-responsiveness of disordered ELPs with the structural stability of poly(L-alanine) helices. Machado et al. also reported the hierarchical self-assembly of $\mathrm{PEO}_{43^{-}}$ Lys $_{62}-$ Leu $_{72}$ to form, through a diffusion-limited aggregation (DLA) process, fractal assemblies at very specific conditions, i.e. $0.10 \% \mathrm{w} / \mathrm{w}$ and $\mathrm{pH} 2$ as the solutions dried on a Transmission Electron Microscopy grid. Interestingly, interparticle and particle-surface interactions were shown to have an effect on the structure of $\mathrm{PEO}_{43}-\mathrm{Lys}_{62}-\mathrm{Leu}_{72}$ fractals. ${ }^{62}$ In our work, the interaction between ELP(Gal) and $\mathrm{RCA}_{120}$ allows the formation of such structures, most likely because $\mathrm{RCA}_{120}$ possesses two binding sites in its native form. As reported in the literature, the preparation of stimuli responsive glycopolymers that are able to simultaneously enhance and control the lectin-glycopolymer interaction is challenging, but has also been achieved by several research groups. ${ }^{63-66}$ Heise et al. reported the synthesis of a glycopolypeptide via ring opening polymerization and click chemistry with combined lectin recognition and thermoresponsive 
properties. ${ }^{67}$ Additionally, similar aggregation behavior to the one evidenced in this work was also observed for thermoresponsive polymers with pendant glucose functionality, which formed aggregates with bacterial cells and were assembled/disassembled reversibly through temperature cycling. ${ }^{68}$

To study binding specificity in a physiological medium, mixtures of $\mathrm{RCA}_{120}$-Fluorescein and ELP(Gal) were prepared in presence of $10 \%$ or $100 \%$ human serum, Figures 5e and 5f, respectively (more details and centrifugation assays in Figure S14). $\mathrm{RCA}_{120}$-Fluorescein in 10\% serum was also analyzed in order to detect possible interactions of the protein with serum components (Figure 5d). Only very few microscopic particles of RCA R20 $_{12}$-Fluorescein were observed in $10 \%$ serum, in contrast to the abundant fractal aggregates observed when $\mathrm{RCA}_{120^{-}}$ Fluorescein and $\operatorname{ELP}(\mathrm{Gal})$ were incubated in the same conditions. When serum concentration was increased to $100 \%$, similar results were obtained although aggregates were more separated from each other, which could be due to the presence of greater amounts of different macromolecules present in serum. However, it is is it important to note that the binding affinity between $\operatorname{ELP}(\mathrm{Gal})$ and $\mathrm{RCA}_{120}$ still occurred in such a complex mixture.

Altogether, our results demonstrate that thermosensitive ELP glycoconjugates can be used to specifically aggregate and pull-down specific lectins by temperature-triggered aggregation and centrifugation. Notably, the entire purification process can be performed within a reasonable temperature range that limits protein denaturation. 

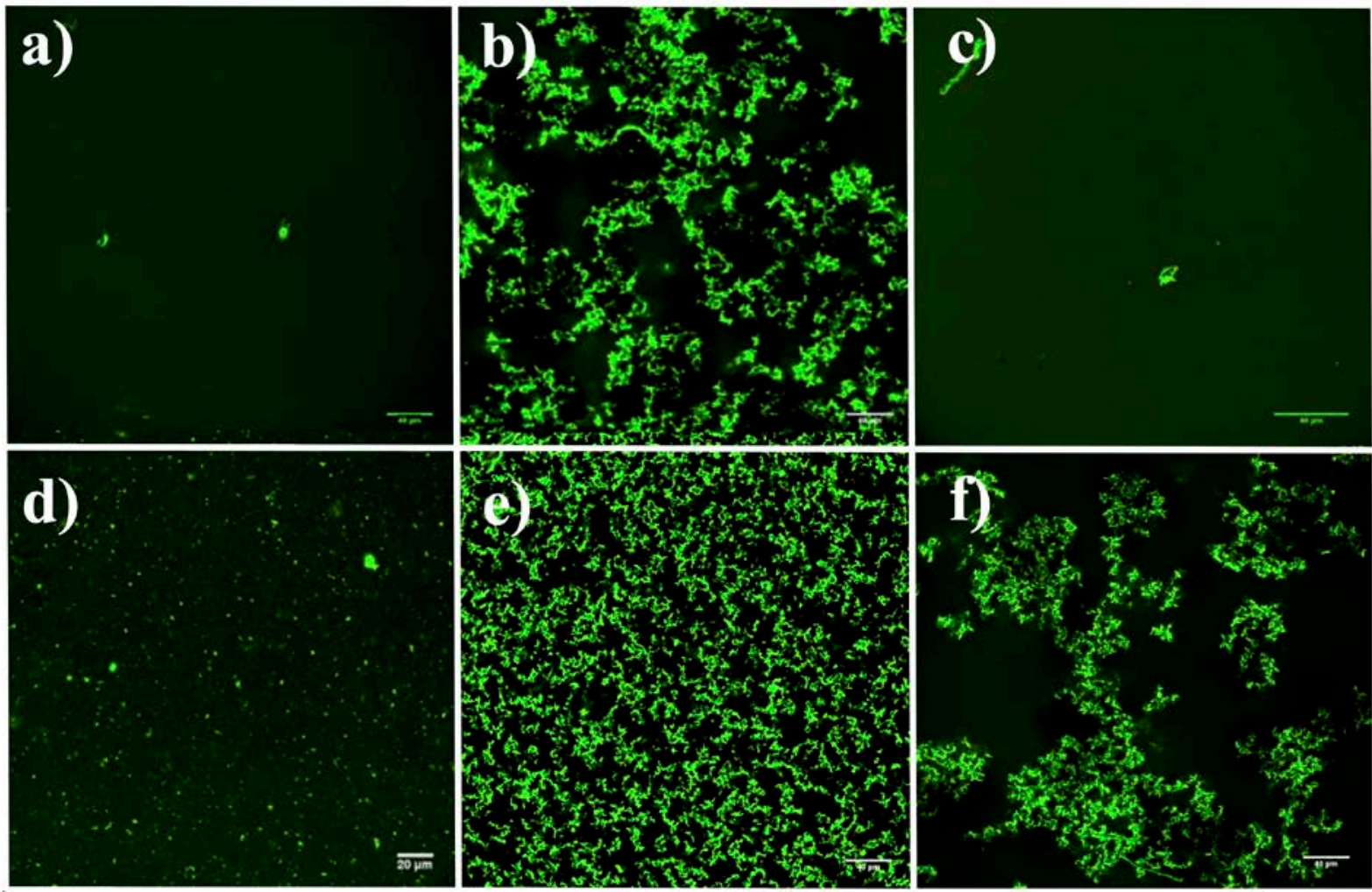

Figure 5. Fluorescence microscopy images (green channel) captured after incubation at $37^{\circ} \mathrm{C}$

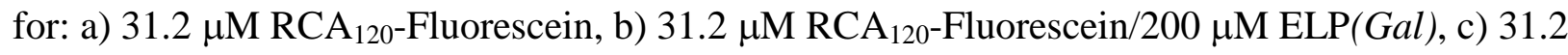

$\mu \mathrm{M}$ RCA $_{120}$-Fluorescein/200 $\mu \mathrm{M}$ ELP(Glc), d) $31.2 \mu \mathrm{M} \mathrm{RCA}_{120}$-Fluorescein in $10 \%$ serum, e)

$31.2 \mu \mathrm{M}_{\mathrm{RCA}}{ }_{120}$-Fluorescein/200 $\mu \mathrm{M}$ ELP(Gal) in 10\% serum, f) $31.2 \mu \mathrm{M} \mathrm{RCA}_{120^{-}}$

Fluorescein/200 $\mu \mathrm{M}$ ELP(Gal) in $100 \%$ serum. 
We have reported the design and synthesis of uniform thermosensitive glycopolypeptide-based on recombinant ELP scaffolds for selective lectin-binding and sorting. Thermoresponsive properties of the resulting ELP derivatives were evaluated and showed that alkylation/demethylation of periodic methionine residues in ELPs allows the modulation of $\mathrm{T}_{\mathrm{t}}$ and the introduction of reactive functional groups. These were used to prepare multivalent galactose or glucose-bearing ELPs that possessed $\mathrm{T}_{\mathrm{t}}$ values in the range of $33-40{ }^{\circ} \mathrm{C}$ and $36-44$

${ }^{\circ} \mathrm{C}$, respectively, at concentrations ranging from 30 to $600 \mu \mathrm{M}$. The binding of $\mathrm{ELP}(\mathrm{Gal})$ towards RCA $_{120}$ lectin was investigated using light and fluorescence microscopy, DLS measurements and centrifugation/precipitation assays, which confirmed the ability of $\operatorname{ELP}(\mathrm{Gal})$ to specifically bind $\mathrm{RCA}_{120}$ lectin. It was found that, aqueous mixtures of thermosensitive $\operatorname{ELP}(\mathrm{Gal})$ with $\mathrm{RCA}_{120}$ lectin above the $\mathrm{T}_{\mathrm{t}}$ could be centrifuged to separate and collect the enriched interacting species in the pellet. An ELP glycoconjugate was found to aggregate and pull down a specific lectin by simple temperature-triggered aggregation and centrifugation at reasonable temperature that maintains protein folding and activity. Based on these results, ELP glycoconjugates show promise as designer biopolymers for selective protein binding and sorting.

\section{ASSOCIATED CONTENT}

\section{Supporting Information.}

Experimental and synthetic procedures, NMR spectra $\left({ }^{1} \mathrm{H}\right.$ and HSQC), SEC traces, DLS temperature ramps and additional fluorescence and microscopy images are available in the supporting information. 


\section{AUTHOR INFORMATION}

\section{Corresponding Author}

*Mailing address: Department of Bioengineering, 5121 Engineering 5, HS-SEAS, University of California, Los Angeles, CA 90095 USA. E-mail: demingt@seas.ucla.edu.

*Mailing address: Université de Bordeaux/Bordeaux INP, ENSCBP, 16 avenue Pey-Berland, 33607 Pessac Cedex, France. E-mail: lecommandoux@enscbp.fr.

\section{Author Contributions}

The manuscript was written through contributions of all authors. All authors have given approval to the final version of the manuscript.

\section{Funding Sources}

This work was supported by the French National Research Agency (ANR-15-CE07-0002), the Cancéropole Grand Sud-Ouest (Emergence 2018-E18) and the foundation Philippe. Financial support from Centre National de la Recherche Scientifique (CNRS), the NSF under MSN 1412367 and MSN 1545634, Université de Bordeaux, and Bordeaux INP is gratefully acknowledged.

\section{ACKNOWLEDGMENT}

L.M. Bravo-Anaya acknowledges the fellowship grant given by CONACYT (CVU 350759) as well as Christophe Schatz for fruitful discussions. The help of Amélie Vax for SEC measurements and Guillaume Goudounet for ELP production is particularly acknowledged. This work was also supported by the French National Research Agency (ANR-15-CE07-0002), the Cancéropole Grand Sud-Ouest (Emergence 2018-E18) and the foundation Philippe. Financial 
support from Centre National de la Recherche Scientifique (CNRS), the NSF under MSN 1412367 and MSN 1545634, Université de Bordeaux, and Bordeaux INP is gratefully acknowledged.

\section{ABBREVIATIONS}

ACN, acetonitrile; CuAAC, $\mathrm{Cu}^{\mathrm{I}}$ - catalyzed azide/alkyne cycloaddition; DLS, dynamic light scattering; ELPs, Elastin-like polypeptides; Gal, Galactose; Glc, glucose; HIV, Human immunodeficiency virus; LCST, lower critical solution temperature; Met, Methionine; NMR, Nuclear magnetic resonance; PEG, Polyethylene glycol; PMDETA, Pentamethyldiethylenetriamine; RCA 120 , Ricinus communis agglutinin; SEC, Size-exclusion chromatography; $\mathrm{T}_{\mathrm{t}}$, transition temperature.

\section{REFERENCES}

(1) Kaur, M.; Singh, K.; Rup, P.J.; Saxena, A.K.; Khan, R.H.; Ashraf, M.T.; Kamboj, S.S.; Singh, A tuber lectin from Arisaema helleborifolium Schott with anti-insect activity against melon fruit fly, Bactrocera cucurbitae (Coquillett) and anti-cancer effect on human cancer cell lines. J. Arch. Biochem. Biophys. 2006, 445 (1), 156-165.

(2) Sitohy, M.; Doheim, M.; Badr, H. Isolation and characterization of a lectin with antifungal activity from Egyptian Pisum sativum seeds. Food Chem. 2007, 104 (3), 971-979.

(3) Takahashi, K.G., Kuroda, T.; Muroga, K. Purification and antibacterial characterization of a novel isoform of the Manila clam lectin (MCL-4) from the plasma of the Manila clam, Ruditapes philippinarum. Comp. Biochem. Phys. B 2008, 150 (1), 45-52.

(4) da Silva, L.C.N.; Alves, N.M.P.; Castro, M.C.A.B.; Pereira; V.R.A., da Paz, N.V.N.; Coelho, L.C.B.B.; de Figueiredo, R.C.B.Q.; Correia, M.T. Immunomodulatory effects of pCramoll and rCramoll on peritoneal exudate cells (PECs) infected and non-infected with Staphylococcus aureus. Int. J. Biol. Macromol. 2015, 72, 848-854.

(5) Hashim, O. H.; Jayapalan, J.J.; Lee, C.-S. Lectins: an effective tool for screening of potential cancer biomarkers. PeerJ. 2017, 5 (3), 1-30. 
(6) Leong, K.H.; Chung, L.Y.; Noordin, M.I.; Onuki, Y.; Morishita, M.; Takayama, K. K. Lectin-functionalized carboxymethylated kappa-carrageenan microparticles for oral insulin delivery. Carbohydr. Polym. 2011, 86 (2), 555-565.

(7) Neutsch, L.; Wirth, E.M.; Spijker, S.; Pichl, C.; Kahlig, H.; Gabor, F.; Wirth, M. Synergistic targeting/prodrug strategies for intravesical drug delivery--lectin-modified PLGA microparticles enhance cytotoxicity of stearoyl gemcitabine by contact-dependent transfer. $J$. Control. Release 2013, 169 (1-2), 62-72.

(8) Silva, M.L.S.; Gomes, C.; Garcia M.B.Q. Flow lectin affinity chromatography-A model with Sambucus nigra agglutinin. J. Glycobiol. 2017, 6 (1), 1-8.

(9) Quiroga, A.V.; Barrio, D.A.; Añón, M.C. Amaranth lectin presents potential antitumor properties. LWT- Food Sci. Technol. 2015, 60 (1), 478-485.

(10) Füzéry, A.K.; Levin, J.; Chan, M.M.; Chan, D.W. Translation of proteomic biomarkers into FDA approved cancer diagnostics: issues and challenges. Clin. Proteom. 2013, 10 (1), 1-14.

(11) Tang, H.; Hsueh, P.; Kletter, D.; Bern, M.; Haab, B. The detection and discovery of glycan motifs in biological samples using lectins and antibodies: New methods and opportunities. Adv. Cancer Res. 2015, 126, 167-202.

(12) Sharon, N.; Lis, H. History of Lectins: From Hemagglutinins to Biological Recognition Molecules. Glycobiology 200414 (11), 53R-62R.

(13) Belardi, B.; Bertozzi, C.R. Chemical Lectinology: Tools for Probing the Ligands and Dynamics of Mammalian Lectins In Vivo. Chemistry \& Biology 2015, 22 (8), 983-992.

(14) Wesener, D.A.; Dugan, A.; Kiessling, L.L. Recognition of microbial glycans by soluble human lectins. Curr. Opin. Struct. Biol. 2017, 44, 168-178.

(15) Palaniappan, K.K.; Bertozzi, C.R. Glycoproteomics. Chem. Rev. 2016, 116 (23), $14277-14306$.

(16) Palaniappan, K. K.; Pitcher, A. A.; Smart, B. P.; Spiciarich, D. R.; Iavarone, A. T.; Bertozzi, C.R. Isotopic Signature Transfer and Mass Pattern Prediction (IsoStamp): An Enabling Technique for Chemically-Directed Proteomics. ACS Chem. Biol. 2011, 6 (8), 829-836.

(17) Woo, C.M.; Iavarone, A.T.; Spiciarich, D.R.; Palaniappan, K.K.; Bertozzi, C.R.. Isotopetargeted glycoproteomics (IsoTaG): a mass-independent platform for intact $\mathrm{N}$ - and Oglycopeptide discovery and analysis. Nature Methods 2015, 12 (6), 561-567. 
(18) Hudak, J.E.; Bertozzi, C.R. Glycotherapy: new advances inspire a reemergence of glycans in medicine. Chem Biol. 2014, 21 (1), 16-37.

(19) Gou, Y.; Geng, J.; Richards, S.-J.; Burns, J.; Becer, C.R.; Haddleton, D.M. . A Detailed Study on Understanding Glycopolymer Library and Con A Interactions. High-affinity glycopolymer binding to human DC-SIGN and disruption of DC-SIGN interactions with HIV envelope glycoprotein. Polym. Chem. 2013, 51 (12), 2599-2597.

(20) Becer, C.R.; Gibson, M.I.; Geng, J.; Ilyas, R.; Wallis, R.; Mitchell, D.A.; Haddleton, D.M. High-affinity glycopolymer binding to human DC-SIGN and disruption of DC-SIGN interactions with HIV envelope glycoprotein. J. Am. Chem. Soc. 2010, 132 (43), 15130-15132.

(21) Wilkins, L.E.; Badi, N.; Prez, F.D.; Gibson, M.I. Double-Modified Glycopolymers from Thiolactones to Modulate Lectin Selectivity and Affinity. ACS Macro Lett. 2018, 7 (12), $1498-1502$.

(22) Westerlind U. Synthetic glycopeptides and glycoproteins with applications in biological research Beilstein J. Org. Chem. 2012, 8 (1), 804-818.

(23) Meyer, B.; Möller, H. Conformation of Glycopeptides and Glycoproteins. Top. Curr. Chem. 2006, 267, 187-251.

(24) Becker, T.; Dziadek, S.; Wittrock, S.; Kunz, H. Synthetic glycopeptides from the mucin family as potential tools in cancer immunotherapy. Curr. Cancer Drug Targets 2006, 6 (6), 491517.

(25) Lavilla, C.; Yilmaz, G.; Uzunova, V.; Naiper, R.; Becer, C.R.; Heise, A. BlockSequence-Specific Glycopolypeptides with Selective Lectin Binding Properties, Biomacromolecules 2017, 18 (6), 1928-1936.

(26) Marcaurelle, L.A.; Bertozzi, C.R. Recent advances in the chemical synthesis of mucinlike glycoproteins. Glycobiology 2002, 12 (6), 69R-77R.

(27) Thapa, P.; Zhang, R.-Y.; Menon, V.; Bingham, J.-P. Native chemical ligation: a boon to peptide chemistry. Molecules 2014, 19 (9), 14461-14483.

(28) Petitdemange, R.; Garanger E.; Bataille, L.; Dieryck, W; Bathany, K.; Garbay, B.; Deming, T.J.; Lecommandoux, S. Selective tuning of elastin-like polypeptide properties via methionine oxidation. Biomacromolecules 2017, 18 (2), 544-550. 
(29) Petitdemange, R.; Garanger, E.; Bataille, L.; Bathany, K.; Garbay, B.; Deming, T.J.; Lecommandoux S. Tuning thermoresponsive properties of cationic elastin-like polypeptides by varying counterions and side-chains. Bioconjugate Chem. 2017, 28 (5), 1403-1412.

(30) Anastasaki, A.; Haddleton, A.J.; Zhang, Q.; Simula, A.; Droesbeke, M.; Wilson, P.; Haddleton, D.M., Aqueous copper-mediated living radical polymerisation of Nacryloylmorpholine, SET-LRP in water, Macromol. Rapid. Commun. 2014, 35 (10), 965-970.

(31) Cavanagh J.; Fairbrother W. J.; Palmer A. G.; Skelton N.J. Protein NMR Spectroscopy: Principles and Practice, Academic Press, San Diego, CA, 1996.

(32) Wüthrich, K. NMR of Proteins and Nucleic Acids, Wiley, 1986.

(33) Frénoy J.-P.; Tran A.-T.; Bourrillon R., Structure and stability of Ricinus communis haemagglutinin, Biochem. J., 1986, 240 (1), 227-231.

(34) Huang J.; Bonduelle C.; Thévenot J.; Lecommandoux S.; Heise A.; Biologically active polymersomes from amphiphilic glycopeptides, J. Am. Chem. Soc. 2012, 134 (1), 119-122.

(35) Urry D.W. Physical Chemistry of Biological Free Energy Transduction As Demonstrated by Elastic Protein-Based Polymers. J. Phys. Chem. B 1997, 101 (51), 11007-11028.

(36) Urry, D. W.; Long, M. M.; Cox, B. A.; Ohnishi, T.; Mitchell, L. W.; Jacobs, M. The synthetic polypentapeptide of elastin coacervates and forms filamentous aggregates. Biochim. Biophys. Acta. 1974, 371 (2), 597-602.

(37) Luan, C.H.; Harris, R.D.; Prasad, K.U.; Urry, D.W. Differential scanning calorimetry studies of the inverse temperature transition of the polypentapeptide of elastin and its analogues. Biopolymers 1990, 29 (14), 1699-1706.

(38) Meyer, D. E.; Chilkoti, A. Quantification of the effects of chain length and concentration on the thermal behavior of elastin-like polypeptides. Biomacromolecules 2004, 5 (3), 846-851.

(39) Mackay, J.A.; Callahan, D.J.; Fitzgerald, K.N.; Chilkoti, A Quantitative model of the phase behavior of recombinant $\mathrm{pH}$-responsive elastin-like polypeptides.. Biomacromolecules 2010, 11 (11), 2873-2879.

(40) McDaniel, J. R.; Radford, D. C.; Chilkoti, A. A Unified Model for De Novo Design of Elastin-like Polypeptides with Tunable Inverse Transition Temperatures. Biomacromolecules 2013, 14 (8), 2866-2872. 
(41) McDaniel, J.R.; Bhattacharyya, J.; Vargo, K.B.; Hassouneh, W.; Hammer, D.; Chilkoti, A. Self-assembly of thermally responsive nanoparticles of a genetically encoded peptide polymer by drug conjugation. Angew. Chem. Int. Ed. Engl. 2013, 52 (6), 1683-87.

(42) Fluegel, S.; Buehler, J.; Fischer, K.; McDaniel, J.R.; Chilkoti, A.; Schmidt, M. SelfAssembly of Monodisperse Oligonucleotide-Elastin Block Copolymers into Stars and Compound Micelles. Chemistry 2011, 17 (20), 5503-6.

(43) Dreher, M.R.; Raucher, D.; Balu, N.; Colvin, O.M.; Ludeman, S.M.; Chilkoti, A. Evaluation of an elastin-like polypeptide-doxorubicin conjugate for cancer therapy. J. Control. Release 2003, 91 (1-2), 31-43.

(44) Van Eldijk, M.B.; Smits, F.C.M.; Vermue, N.; Debets, M. F.; Schoffelen, S.; van Hest, J.C.M. Synthesis and self-assembly of well-defined elastin-like polypeptide-poly (ethylene glycol) conjugates. Biomacromolecules 2014, 15 (7), 2751-59.

(45) Seifried, B.M.; Cao, J.; Olsen, B.D. Multifunctional, High Molecular Weight, PostTranslationally Modified Proteins through Oxidative Cysteine Coupling and Tyrosine Modification. Bioconjugate Chem. 2018, 29 (6), 61876-1884.

(46) Bravo-Anaya, L.M.; Garbay, B.; Nando-Rodríguez, J.L.E.; Carvajal Ramos, F.; Ibarboure, E.; Bathany, K.; Xia, Y.; Rosselgong, J.; Joucla, G.; Garanger, E.; Lecommandoux, S. Nucleic acids complexation with cationic elastin-like polypeptides: Stoichiometry and stability of nano-assemblies. J. Colloid Interface Sci. 2019, 557, 777-792.

(47) Rosselin, M.; Xiao, Y.; Belhomme, L.; Lecommandoux, S.; Garanger, E. Expanding the Toolbox of Chemoselective Modifications of Protein-Like Polymers at Methionine Residues. ACS Macro Letters 2019, 8 (12), 1648-1653.

(48) Liang, L.; Astruc, D. The copper (I)-catalyzed alkyne-azide cycloaddition (CuAAC)“click” reaction and its applications. An overview. Coord. Chem. Rev. 2011, 255 (2324), 2933-2945.

(49) Rostovtsev, V.V.; Green, L. G.; Fokin, V.V.; Sharpless, K.B. A stepwise huisgen cycloaddition process: copper(I)-catalyzed regioselective "ligation" of azides and terminal alkynes. Angew. Chem. Int. Ed. 2002, 41 (14), 2596-2599.

(50) Kramer, J.R.; Deming, T.J. Reversible chemoselective tagging and functionalization of methionine containing peptides. Chem. Commun. 2013, 49 (45), 5144-5146. 
(51) Abdullah, A.H.; Fuaad, A.; Azmi, F.; Skwarczynski, M.; Toth, I. Peptide conjugation via CuAAC 'click'chemistry. Molecules 2013, 18 (11), 13148-13174.

(52) Kramer, J.R.; Petitdemange, R.; Bataille, L.; Bathany, K.; Wirotius, A.-L.; Garbay, B.; Deming, T.J.; Garanger, E.; Lecommandoux, S. Quantitative side-chain modifications of methionine-containing elastin-like polypeptides as a versatile tool to tune their properties. ACS Macro Lett. 2015, 4 (11), 1283-1286.

(53) Dwek, R.A. Glycobiology: toward understanding the function of sugars. Chem. Rev. 1996, 96 (2), 683-720.

(54) Miyajima, K.; Machida, K.; Taga, T.; Komatsu, H.J. Correlation between the hydrophobic nature of monosaccharides and cholates, and their hydrophobic indices. Faraday Trans. 1 1988, 84 (8), 2537-2544.

(55) Pecora, R. J. Dynamic light scattering measurement of nanometer particles in liquids. Nanoparticle Res. 2000, 2 (2), 123-131.

(56) Petta, V.; Pharmakakis, N.; Papatheodorou, G.N.; Yannopoulos, S.N. Dynamic light scattering study on phase separation of a protein-water mixture: Application on cold cataract development in the ocular lens. Phys. Rev. E 2008, 77, 1-40.

(57) Wang, Y.; Yu, G.; Han, Z.; Yang, B.; Hu, Y.; Zhao, X.; Wu, J.; Lv, Y.; Chai, W. Specificities of Ricinus communis agglutinin 120 interaction with sulfated galactose. FEBS Lett. 2011, 585 (24), 3927-3934.

(58) Ma, Z.; Jia, Y.-G.; Zhu, X.X. Glycopolymers Bearing Galactose and Betulin: Synthesis, Encapsulation, and Lectin Recognition, Biomacromolecules 2017, 18 (11), 3812-381.

(59) Jullien, R. Aggregation phenomena and fractal aggregates Contemp. Phys., 1987, 28 (5), 477-493.

(60) Witten, T.A.; Sander, L.M. Diffusion-limited aggregation. Physical review B 1983, 27 (9), 5686-5697.

(61) Roberts, S.; Harmon, T.S.; Schaal, J.; Miao, V.; Li, K.J.; Hunt, A.; Wen, Y.; Oas, T.G.; Collier, J.H.; Pappu, R.V.; Chilkoti, A. Injectable tissue integrating networks from recombinant polypeptides with tunable order. Nat. Mater. 2018, 17 (18), 1154-1163.

(62) Machado, C.A.; Bentz, K.C.; Tran, R.; Jenkins, T.A.; Barnes, B.E.; Diodati, L.E.; Savin, D.A. Hierarchical Fractal Assemblies from Poly(ethylene oxide-b-lysine-b-leucine), Biomacromolecules 2019, 20 (7), 2557-2566. 
(63) Vandewalle, S.; Wallyn, S.; Chattopadhyay, S. Thermoresponsive hyperbranched glycopolymers: Synthesis, characterization and lectin interaction studies, Eur. Polym. J. 2015, 69, 490-498.

(64) Cakir, N.; Hizal, G.; Becer, C.R. Supramolecular glycopolymers with thermo-responsive self-assembly and lectin binding, Polym. Chem., 2015, 6, 6623-6631.

(65) von der Ehe, C.; Weber, C.; Wagner, M.; Czaplewska, J.A.; Gottschaldt, M.; Schubert, U.S. Synthesis of Thermoresponsive Glycopolymers Combining RAFT Polymerization, Thiol-Ene Reaction, and Subsequent Immobilization onto Solid Supports, Macromol. Chem. Phys., 2014, 215 (13), 1306-1318.

(66) Paul, T.J.; Rübel, S.; Hildebrandt, M.; Strzelczyk, A.K.; Spormann, C.; Lindhorst, T.K.; Schmidt, S. Thermosensitive Display of Carbohydrate Ligands on Microgels for Switchable Binding of Proteins and Bacteria, ACS Appl. Mater. Interfaces 2019, 11 (30), 26674-26683.

(67) Kapetanakis, A.; Heise, A. Thermoresponsive glycopolypeptides with temperature controlled selective lectin binding properties, Eur. Polym. J. 2015, 69, 483-489.

(68) Pasparakis, G.; Cockayne, A.; Alexander, C. Control of Bacterial Aggregation by Thermoresponsive Glycopolymers, J. Am. Chem. Soc. 2007, 129 (36), 11014-11015.

TOC

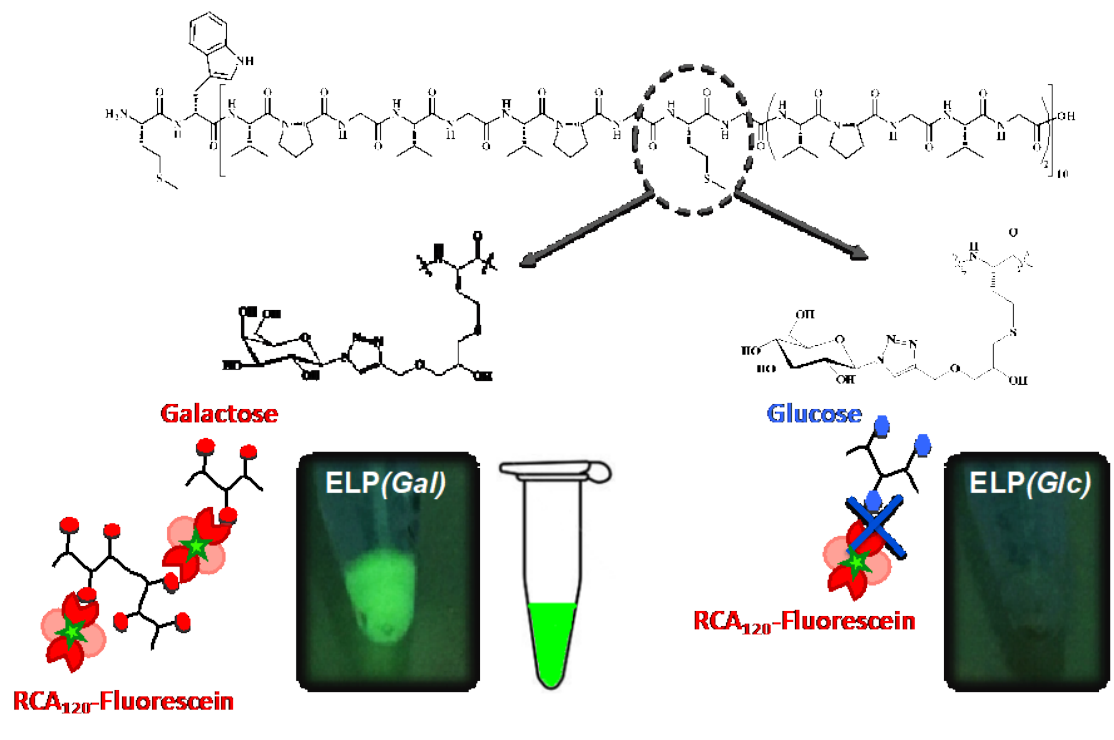

Selective binding and sorting

No interaction 


\title{
Supporting Information
}

for

\section{Design of thermoresponsive elastin-like glycopolypeptides for selective lectin binding and sorting}

\author{
Lourdes Mónica Bravo Anaya, Rosine Petitdemange, Marie Rosselin, Emmanuel Ibarboure, Bertrand \\ Garbay, Elisabeth Garanger, Timothy J. Deming* and Sebastien Lecommandoux* \\ Univ. Bordeaux, CNRS, Bordeaux INP, LCPO, UMR 5629, Pessac, F-33600, France. \\ Department of Chemistry and Biochemistry, and Department of Bioengineering, University of \\ California, Los Angeles, California 90095, United States.
}

\section{Experimental Procedures}

\section{Materials}

Bacto-tryptone and yeast extract were obtained from Biokar Diagnostics (FR). LB medium was purchased from Sigma-Aldrich (FR). Ampicillin was purchased from Eurobio (FR). Glycerol and isopropyl $\beta$-D-thiogalactopyranoside (IPTG) were purchased from Euromedex (FR). Glycidyl propargyl ether was obtained from Sigma-Aldrich (Saint-Quentin-Fallavier, FR). Glacial acetic acid, Trizma $\Omega$ and Hexafluoroisopropanol (HFIP) were obtained from Sigma-Aldrich (FR). Deionized water (18 M $\Omega$-cm) was obtained by using a Millipore Milli-Q Biocel A10 purification unit. Cuprisorb was purchased from Seachem. Ethanol $(96.0 \%$, EtOH), methanol $(98.5 \%, \mathrm{MeOH})$ and acetonitrile $(99.9 \%, \mathrm{ACN})$ were obtained from VWR international. $\mathrm{NaCl}(99 \%)$ was purchased from Alfa Aesar (FR). Azide monosaccharides ( $\beta$-D-galactopyranosyl azide, Gal- $\mathrm{N}_{3}$; and $\beta$-D-glucopyranosyl azide (Glu- $\mathrm{N}_{3}$ ) were obtained from Carbosynth (UK). Ammonium Acetate and Ammonium pyrrolidinedithiocarbamate, APDC, were purchased from Fisher Scientific (FR). $R_{C A} A_{120}$ and $R C A_{120}$-Fluorescein were purchased from Eurobio (FR). Human serum from human male AB plasma, USA origin, sterilefiltered, was used as received from Sigma-Aldrich (FR). N,N,N',N",N"- pentamethyldiethylenetriamine (PMDETA) was purchased from Sigma-Aldrich (FR). $\mathrm{CuSO}_{4} \cdot 5 \mathrm{H}_{2} \mathrm{O}$ was obtained from VWR (FR). Sodium ascorbate was obtained from Fisher Scientific (FR).

\section{Bioproduction of recombinant ELP}

ELP (MW[VPGVGVPGMG(VPGVG) $\left.{ }_{2}\right]_{10}$ ) was bio-produced, isolated and purified according to the procedures established by R. Petitdemange et al. 2017 [1]. ELP gene sequences and those of the corresponding protein were reported also by R. Petitdemange et al. 2017 [1].

\section{Synthetic procedures}

Modification of ELP using epoxides [1]<smiles>C#CCOCC(O)C[S](C)CC[C@H](NC(C)C)C(C)=O</smiles>
A $50 \mathrm{mg}$ sample of MW-[(VPGVG) (VPGMG) (VPGVG) $]_{10}$ was dissolved in $2.5 \mathrm{~mL}$ of an AcOH/HFIP mixture $(9 / 1, \mathrm{v} / \mathrm{v})(20 \mathrm{mg} / \mathrm{mL})$. ELP solution was degassed by bubbling $\mathrm{N}_{2}$ into the solution for $1 \mathrm{~h}$, which was then stirred under $N_{2}$. Glycidyl propargyl ether was then added to the mixture (10 equiv. per methionine residue), which was stirred for $48 \mathrm{~h}$ under $\mathrm{N}_{2}$ at room temperature. The obtained mixture was transferred into a $3000 \mathrm{MWCO}$ centrifugal filter tube and washed with $40 \mathrm{~mL}$ DI water. The remaining content of the centrifugal filter tube was lyophilized to obtain the product ELP(Alkyne) as a white solid.

Details of ELP(Alkyne): ${ }^{1} \mathrm{H}$ NMR $\left(400 \mathrm{MHz}, \mathrm{D}_{2} \mathrm{O}, 25^{\circ} \mathrm{C}\right)$ : (main peaks) $\delta 4.5-4.4(\mathrm{~m}, 80 \mathrm{H}, \alpha \mathrm{CH}$

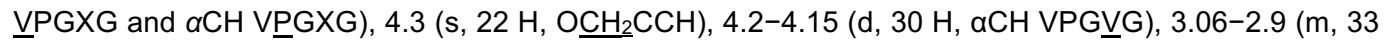
$\left[\mathrm{M}_{11}\right]^{11+}=1661.8 \mathrm{Da}$. Yield $=97 \%$. $\left.\overline{\mathrm{H}}, \mathrm{SCH}_{3}\right), 1.00-0.7 \overline{5}\left(\mathrm{br} \mathrm{m}, 420 \mathrm{H}, \mathrm{CH}_{3} \overline{\mathrm{Val}}\right) . \mathrm{MS}-\mathrm{ESI}$ : Theoretical MW = $18279.1 \mathrm{Da}$, Experimental 


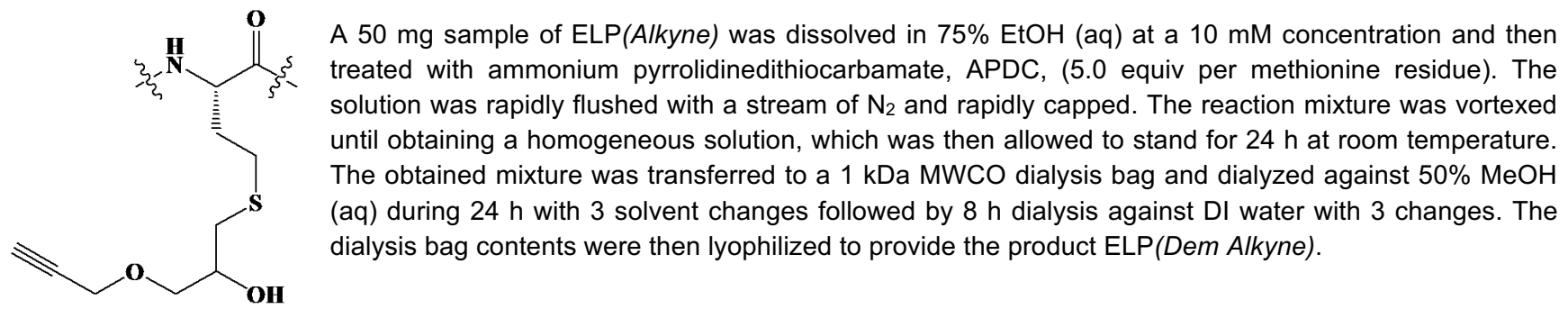

Details of ELP(Dem Alkyne): ${ }^{1} \mathrm{H}$ NMR (400 MHz, $\left.\mathrm{D}_{2} \mathrm{O}, 25^{\circ} \mathrm{C}\right)$ : (main peaks) $\delta 4.5-4.4(\mathrm{~m}, 80 \mathrm{H}, \alpha C H \underline{\mathrm{VPGXG}}$ and $\alpha \mathrm{CH}$ VPGXG), 4.25 (s, $22 \mathrm{H}, \mathrm{OCH}_{2} \mathrm{CCH}$ ), 4.2-4.15 (d, $30 \mathrm{H}, \mathrm{aCH}$ VPGG), 2.8-2.55 (m, $44 \mathrm{H}, \underline{\mathrm{CH}_{2}} \mathrm{SCH}_{2}$ ), 1.00-0.75 (br m, $\left.420 \mathrm{H}, \mathrm{CH}_{3} \mathrm{Val}\right)$. MSESI: Theoretical $\mathrm{MW}=18113.8 \mathrm{Da}$, Experimental $\left[\mathrm{M}_{11}+2 \mathrm{H}^{13+}=1394.7 \mathrm{Da} ;\left[\mathrm{M}_{11}+3 \mathrm{Na}\right]^{14+}=1298.2 \mathrm{Da}\right.$. Yield $=65 \%$.

\section{Synthesis of ELP glycoconjugates.}

A sample of ELP(Dem Alkyne) was dissolved in water $(5 \mathrm{mg} / \mathrm{mL})$ and the desired azido-functionalized monosaccharide, either $\beta$-Dgalactopyranosyl azide or $\beta$-D-glucopyranosyl azide (powder, 1.5 equiv. per alkyne) was added. The solution was degassed by bubbling $\mathrm{N}_{2}$ for $2 \mathrm{hrs}$ and then stirred under $\mathrm{N}_{2}$. Separately, a solution of $\mathrm{Cu}(\mathrm{I})$ was prepared by addition of sodium ascorbate $(0.65$ equiv. per alkyne) to a degassed solution of $\mathrm{Cu}(\mathrm{II}) \mathrm{SO}_{4}(0.13$ equiv. per alkyne) and pentamethyldiethylenetriamine $(0.13$ equiv. per alkyne). The $\mathrm{Cu}(\mathrm{I})$ solution then was transferred to the reaction mixture with a syringe. The reaction was stirred under $\mathrm{N}_{2}$ at room temperature for $72 \mathrm{hrs}$. Cuprisorb $(100 \mathrm{mg})$, a powerful absorbent of copper [2], was added to the reaction mixture and stirred overnight. Cuprisorb beads were separated by centrifugation and the supernatant was transferred to a $3000 \mathrm{MWCO}$ centrifugal filter tube, which was washed first with an aqueous solution of EDTA $(0.15 \mathrm{M})$ and then with $40 \mathrm{~mL}$ DI water. The purified reaction mixture was then lyophilized to provide the ELP glycoconjugate as a white solid.

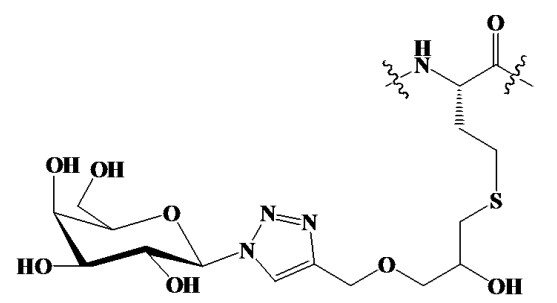

Details of ELP(Gal): $\operatorname{ELP}(G a l)$ was prepared from ELP(Dem Alkyne) and $\beta-D-$ galactopyranosyl azide $\left(\mathrm{Gal}-\mathrm{N}_{3}\right)$. Yield $=85 \%$; ${ }^{1} \mathrm{H}$ NMR $\left(400 \mathrm{MHz}, \mathrm{D}_{2} \mathrm{O}, 25{ }^{\circ} \mathrm{C}\right)$ : (main peaks) $\delta$ 8.4-8.3 (br s, $11 \mathrm{H}$, triazole-H) 5.85-5.7 (br s, $11 \mathrm{H}$, anomeric- $\mathrm{H}), 4.5-4.4(\mathrm{~m}, 80 \mathrm{H}$, $\alpha C H \underline{V} P G X G$ and $\alpha C H$ V $\underline{G}$ GG), 4.2-4.15 (d, $30 \mathrm{H}, \alpha C H$ VPG $\underline{V}$ ), 1.00-0.75 (br m, $420 \mathrm{H}$, $\mathrm{CH}_{3}$ Val). Theoretical MW $=20369.7 \mathrm{Da}$.

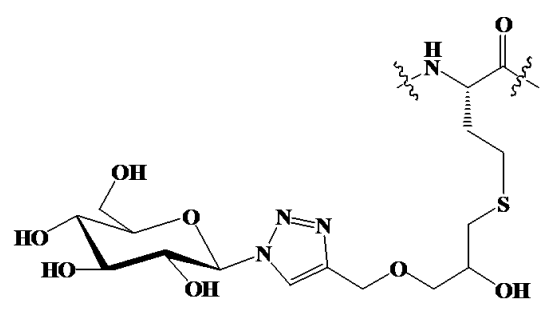

Details of ELP(G/c): $\operatorname{ELP}(G / c)$ was prepared from $\operatorname{ELP}($ Dem Alkyne) and $\beta$-Dglucopyranosyl azide $\left(\mathrm{Glc}_{\mathrm{N}} \mathrm{N}_{3}\right)$. Yield $=88 \% ;{ }^{1} \mathrm{H}$ NMR $\left(400 \mathrm{MHz}, \mathrm{D}_{2} \mathrm{O}, 25{ }^{\circ} \mathrm{C}\right)$ : (main peaks): $\delta$ 8.4-8.3 (br s, $11 \mathrm{H}$, triazole-H) 5.9-5.75 (br s, $11 \mathrm{H}$, anomeric- $\mathrm{H}), 4.5-4.4(\mathrm{~m}, 80 \mathrm{H}$, $\alpha C H \underline{V P G X G}$ and $\alpha C H$ VPGXG), 4.2-4.15 (d, $30 \mathrm{H}, \alpha C H$ VPGG), $2.7 \mathrm{ppm}\left(\mathrm{s}, 9 \mathrm{H}, \mathrm{CH}_{3}\right.$ Met-ox) 1.00-0.75 (br m, $420 \mathrm{H}, \mathrm{CH}_{3}$ Val). Theoretical MW $=20369.7 \mathrm{Da}$.

\section{${ }^{1} H$ NMR analyses}

${ }^{1} \mathrm{H}$ NMR analyses were performed on a Bruker AVANCE III HD 400 apparatus equipped with a 5 mm Bruker multinuclear z-gradient direct probe operating at $400.2 \mathrm{MHz}$ for ${ }^{1} \mathrm{H}$ and $100.6 \mathrm{MHz}$ for ${ }^{13} \mathrm{C}$. An amount of $7 \mathrm{mg}$ of material was dissolved in $0.5 \mathrm{~mL}$ of deuterated solvent $\left(\mathrm{D}_{2} \mathrm{O}\right)$ and 128 scans were recorded for ${ }^{1} \mathrm{H}$ experiments. ${ }^{1} \mathrm{H}$ NMR spectra were acquired in $\mathrm{D}_{2} \mathrm{O}$ at $25{ }^{\circ} \mathrm{C}$. The solvent signal was used as the reference signal $(\delta=4.79 \mathrm{ppm})$. HSQC analyses were performed on a Bruker AVANCE NEO 400 spectrometer operating at $100.7 \mathrm{MHz}$, equipped with a $5 \mathrm{~mm}$ Bruker multinuclear z-gradient direct cryoprobe-head operating at $25^{\circ} \mathrm{C}$. Data processing was performed using Bruker Topspin Software. Chemical shifts of amino acids are well-known in the literature $[3,4]$.

\section{Size Exclusion Chromatography (SEC) analyses}

SEC analyses of ELP derivatives were performed on a liquid chromatographic system from ThermoScientific equipped with two G4000PWXL and G3000PWXL gel columns $(300 \times 7.8 \mathrm{~mm}$ ) (exclusion limits from $200 \mathrm{Da}$ to $300000 \mathrm{Da})$ and UV detector at a flow rate of $0.6 \mathrm{~mL} / \mathrm{min}$. Column temperatures were held at $25^{\circ} \mathrm{C}$. The system includes a multi-angle light scattering detector MALS and differential refractive index detector $\mathrm{dRI}$ from Wyatt technology. Aqueous solvent composed of acetic acid $(\mathrm{AcOH}) 0.3 \mathrm{M}$, ammonium acetate $0.2 \mathrm{M}$ and $\mathrm{ACN}(6.5 / 3.5, \mathrm{v} / \mathrm{v})$ was used as the eluent. Ethylene glycol was used as flow marker.

\section{Transition temperature $\left(T_{t}\right)$ measurements of ELP derivatives}

Dynamic light scattering (DLS) measurements were performed on a Malvern ZetaSizer Nano ZS instrument equipped with a standard $\mathrm{HeNe}$ laser emitting at $632.8 \mathrm{~nm}$ (Malvern, U.K.) at a $90^{\circ}$ angle at a constant position in the cuvette (constant scattering volume). An amount of $100 \mu \mathrm{L}$ of sample was introduced in a high precision cell with a light path of $3 \times 3 \mathrm{~mm}$ made of quartz. Solutions of ELP, $\operatorname{ELP}($ Alkyne), $\operatorname{ELP}(D e m$ Alkyne), $\operatorname{ELP}(G a l)$ and $\operatorname{ELP}(G / c)$, were prepared at a range of concentrations between 0.1 and $2.0 \mathrm{mM}$ in 
Trizma buffer (50 mM Trizma, $0.15 \mathrm{M} \mathrm{NaCl}$ ). The selected buffer allowed conserving a constant $\mathrm{pH}$ (7.5), which was selected to perform carbohydrate-lectin binding experiments in the appropriate conditions to maintain $\mathrm{RCA}_{120}$ conformation and properties [5]. One measurement of four runs ( $10 \mathrm{~s}$ each one) was recorded during a temperature ramp programmed from 15 to $74{ }^{\circ} \mathrm{C}$ every 1.8 degrees after a 2 min-temperature equilibration time. The derived count rate (DCR) was defined as the mean scattered intensity normalized by the attenuation factor. The derived count rate was plotted against temperature and the transition temperature $\left(T_{t}\right)$ was determined by taking the onset of aggregation of the ELP, corresponding to the point where the scattered intensity starts increasing on this plot [1].

\section{Dynamic light scattering (DLS) measurements}

Dynamic light scattering measurements were performed on a Malvern ZetaSizer Nano ZS instrument equipped with a standard HeNe laser emitting at $632.8 \mathrm{~nm}$ (Malvern, U.K.) at a $90^{\circ}$ angle. An amount of $100 \mathrm{~mL}$ of sample was introduced in a high precision cell with a light path of $3 \times 3 \mathrm{~mm}$ made of quartz. The correlation functions were averaged from three measurements of 10 runs ( $30 \mathrm{~s}$ each one) at a temperature of $25^{\circ} \mathrm{C}$ after a 2 min-temperature equilibration time.

\section{Laser Scanning Confocal Microscopy (LSCM)}

Laser Scanning Confocal Microscopy images were acquired on an inverted Leica TCS SP5 microscope equipped with an HCX PL APO 63X, NA 1.4 oil immersion objective in fluorescence mode. The laser outputs were controlled via the Acousto-Optical Tunable Filter (AOTF) and the two collection windows using the Acousto-Optical Beam Splitter (AOBS) and photomultiplier tubes (PMT) as follows: Fluorescein was excited with an argon laser at $488 \mathrm{~nm}(12 \%)$ and measured with emission settings at 500-550 $\mathrm{nm}$. The helium-neon laser at $633 \mathrm{~nm}(10 \%)$ was only used in transmission mode. Images were collected using the microscope in sequential mode with a line average of 8 and a format of $512 * 512$ pixels or $1024^{*} 1024$ pixels. Samples $(\approx 30 \mu \mathrm{L})$ were injected in $\mu$-slide (chambered coverslip) with uncoated 8 wells from Ibidi $\mathrm{GmbH}$. Processing of fluorescence confocal acquisitions were performed with the ImageJ freeware.

\section{Centrifugation/precipitation assays}

Solutions of $\operatorname{ELP}(\mathrm{Gal})$ or $\operatorname{ELP}(\mathrm{Glc})$ at a concentration of $200 \mu \mathrm{M}$ were mixed with RCA-Fluorescein (31.2 $\mu \mathrm{M})$ in Trizma buffer to prepare samples for centrifugation/precipitation assays. After mixture, solutions were incubated under shaking at room temperature for $20 \mathrm{~min}$ to allow the carbohydrate-RCA ${ }_{120}$ interaction to take place [6]. Then, temperature was increased to $37^{\circ} \mathrm{C}$ and samples were incubated for $20 \mathrm{~min}$. Finally, solutions were centrifuged at $40{ }^{\circ} \mathrm{C}$ for 20 minutes at $10,000 \mathrm{~g}$. Supernatant was removed and the pellet was re-suspended in fresh buffer. An UV-Vis lamp at $365 \mathrm{~nm}$ was used to illuminate samples to identify presence of the fluorescence signal.

\section{Additional Figures}

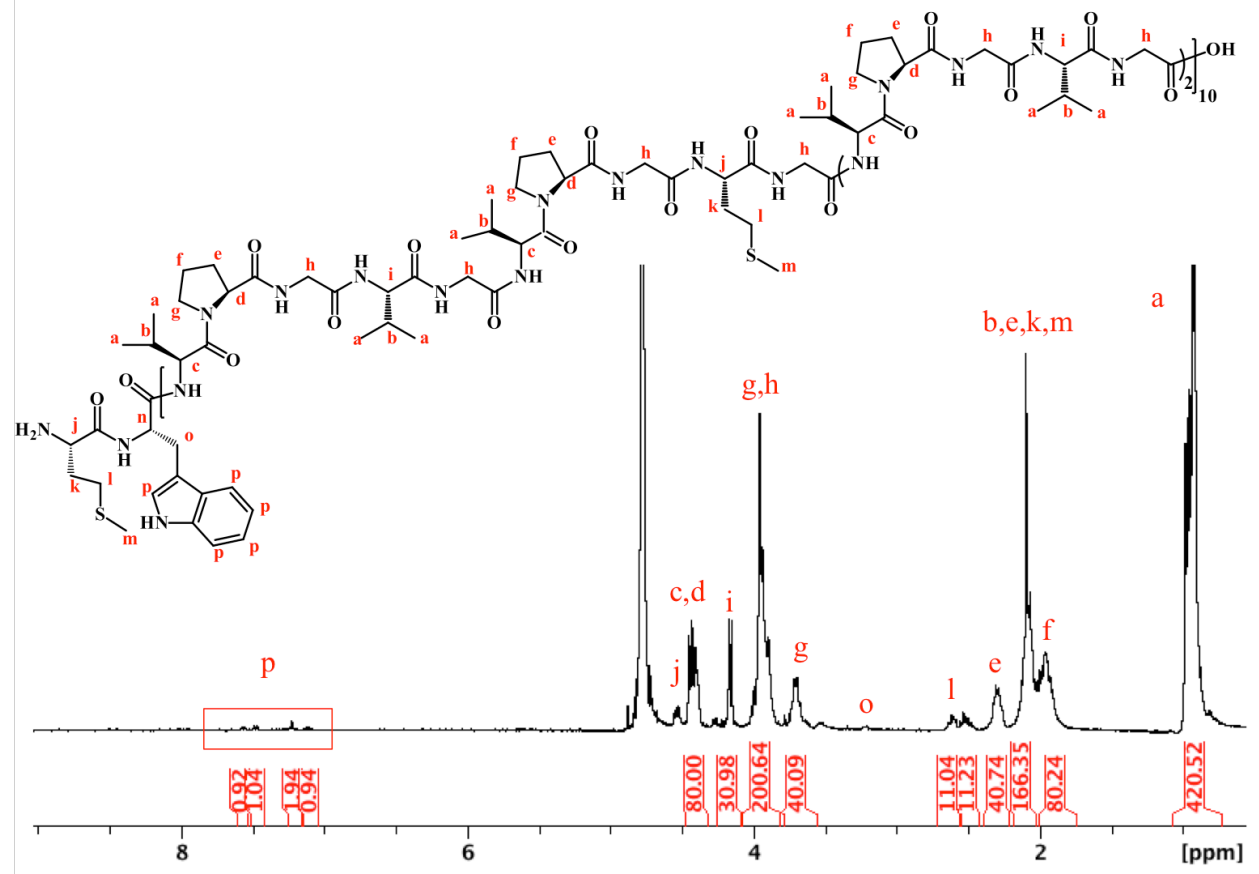

Figure $\mathrm{S} 1 .{ }^{1} \mathrm{H}-\mathrm{NMR}$ spectrum of ELP in $\mathrm{D}_{2} \mathrm{O}$ at $25^{\circ} \mathrm{C}$ 


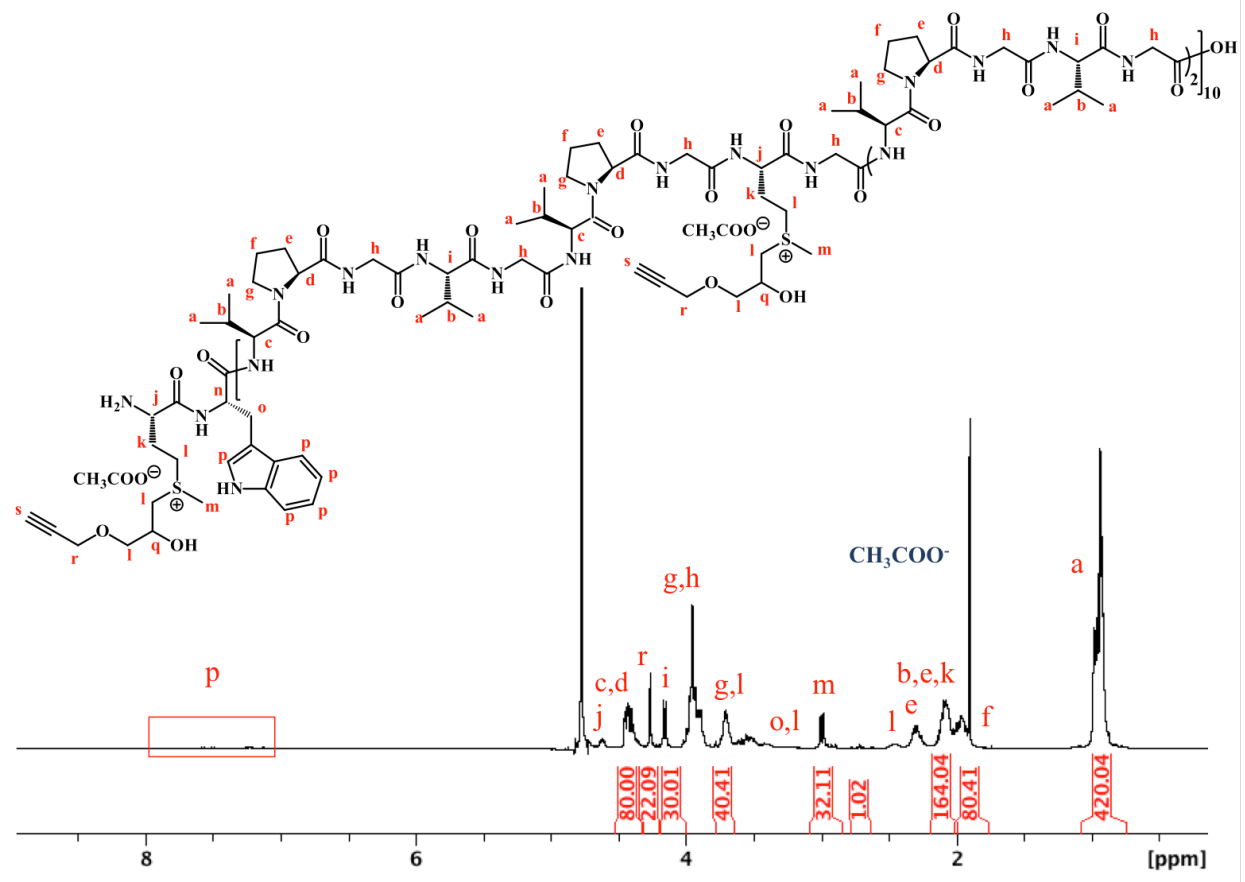

Figure S2. ${ }^{1} \mathrm{H}-\mathrm{NMR}$ spectrum of $\operatorname{ELP}\left(\right.$ Alkyne) in $\mathrm{D}_{2} \mathrm{O}$ at $25^{\circ} \mathrm{C}$.

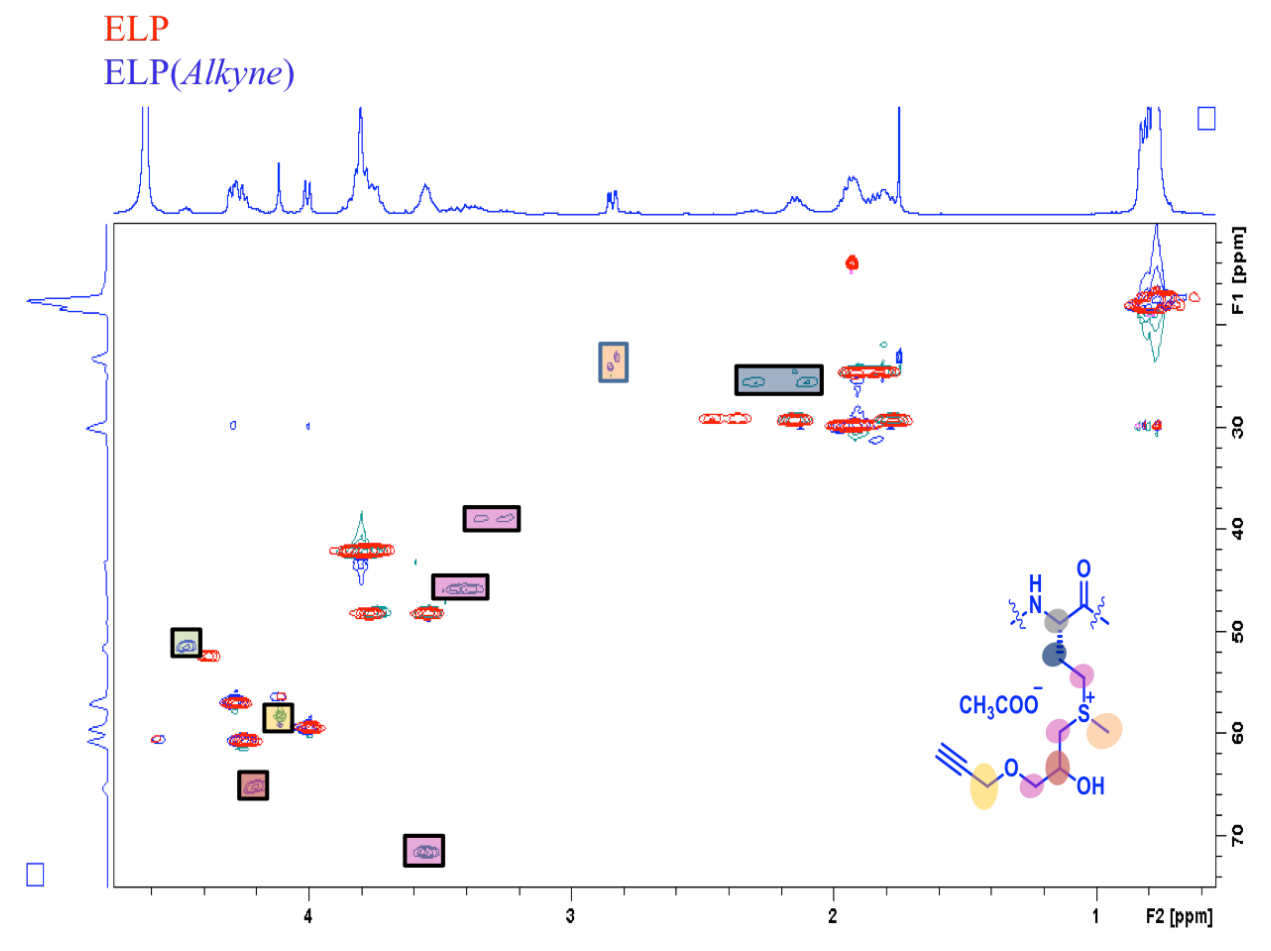

Figure S3. HSQC spectra of ELP (in red) and $\operatorname{ELP}(A l k y n e)$ (in blue and green) in $\mathrm{D}_{2} \mathrm{O}$ at $25^{\circ} \mathrm{C}$. Positive peaks are blue $\left(\mathrm{CH}, \mathrm{CH}_{3}\right)$ and negative peaks are green $\left(\mathrm{CH}_{2}\right)$. 


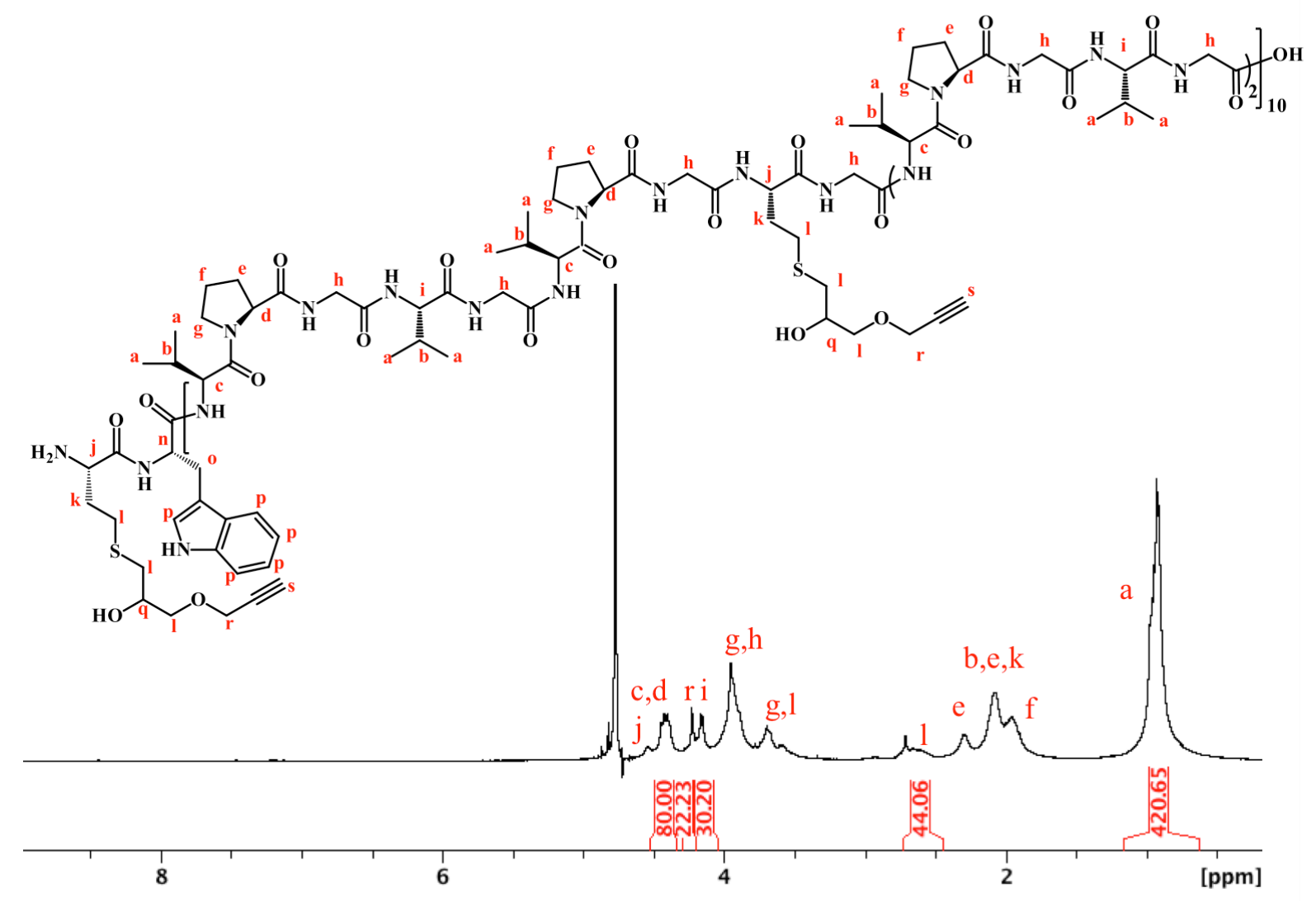

Figure S4. ${ }^{1} \mathrm{H}-\mathrm{NMR}$ spectrum of $\operatorname{ELP}\left(\right.$ Dem Alkyne) in $\mathrm{D}_{2} \mathrm{O}$ at $25^{\circ} \mathrm{C}$.

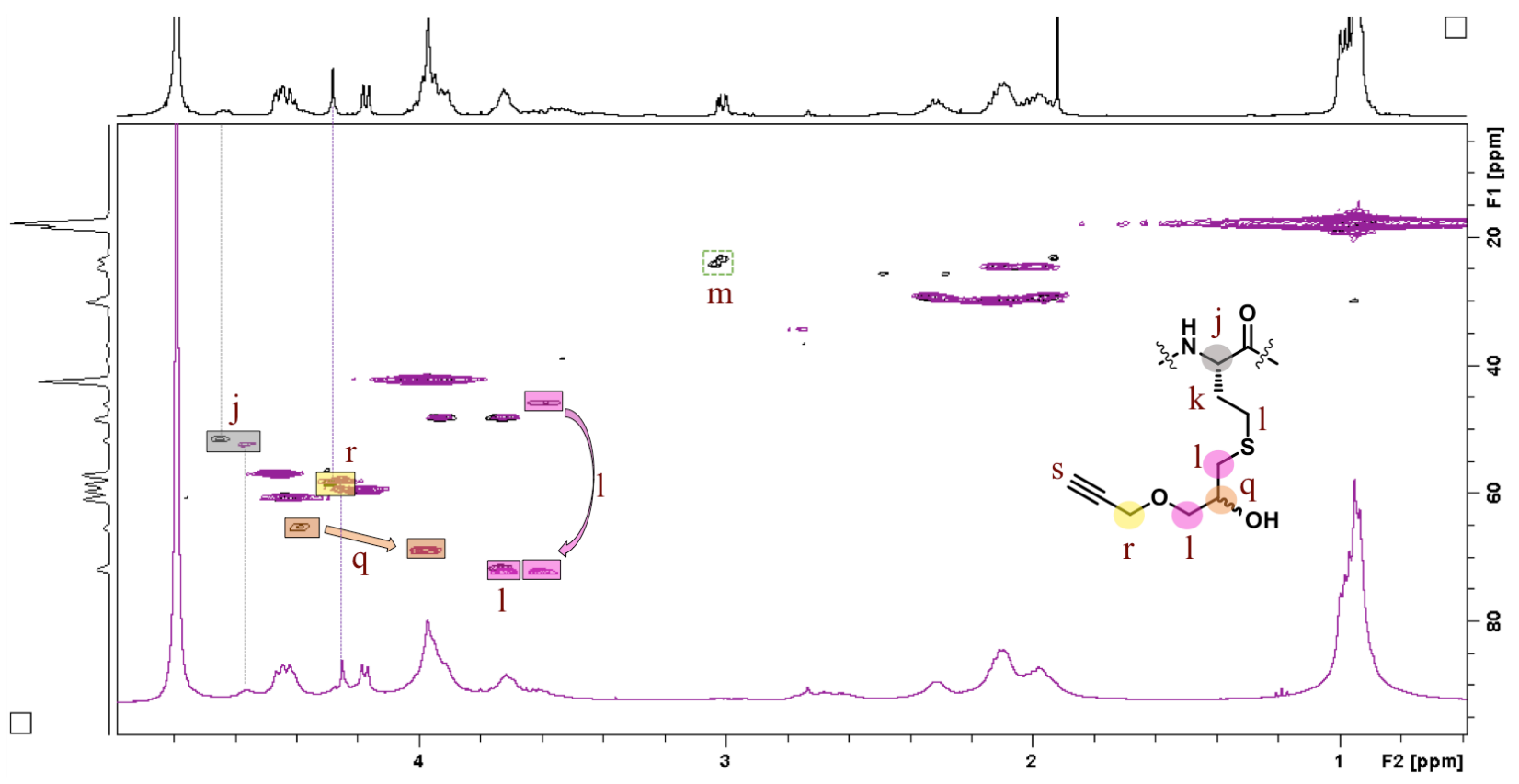

Figure S5. HSQC spectra of $\operatorname{ELP}\left(\right.$ Alkyne) (in black) and b) $\operatorname{ELP}\left(\right.$ Dem Alkyne) (in pink) in $\mathrm{D}_{2} \mathrm{O}$ at $25^{\circ} \mathrm{C}$.

5 


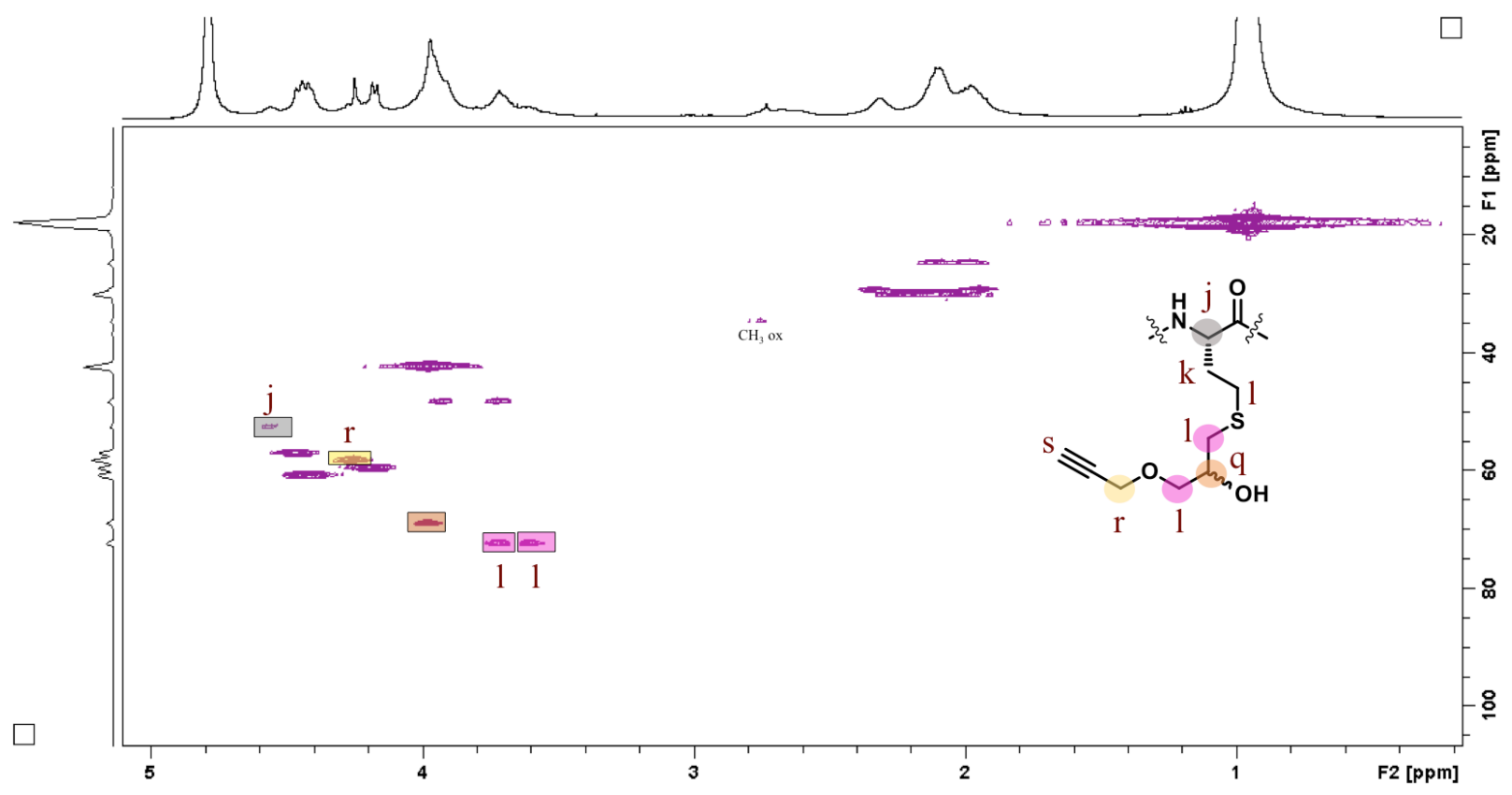

Figure S6. HSQC spectrum of $\operatorname{ELP}\left(\right.$ Dem Alkyne) in $\mathrm{D}_{2} \mathrm{O}$ at $25^{\circ} \mathrm{C}$.

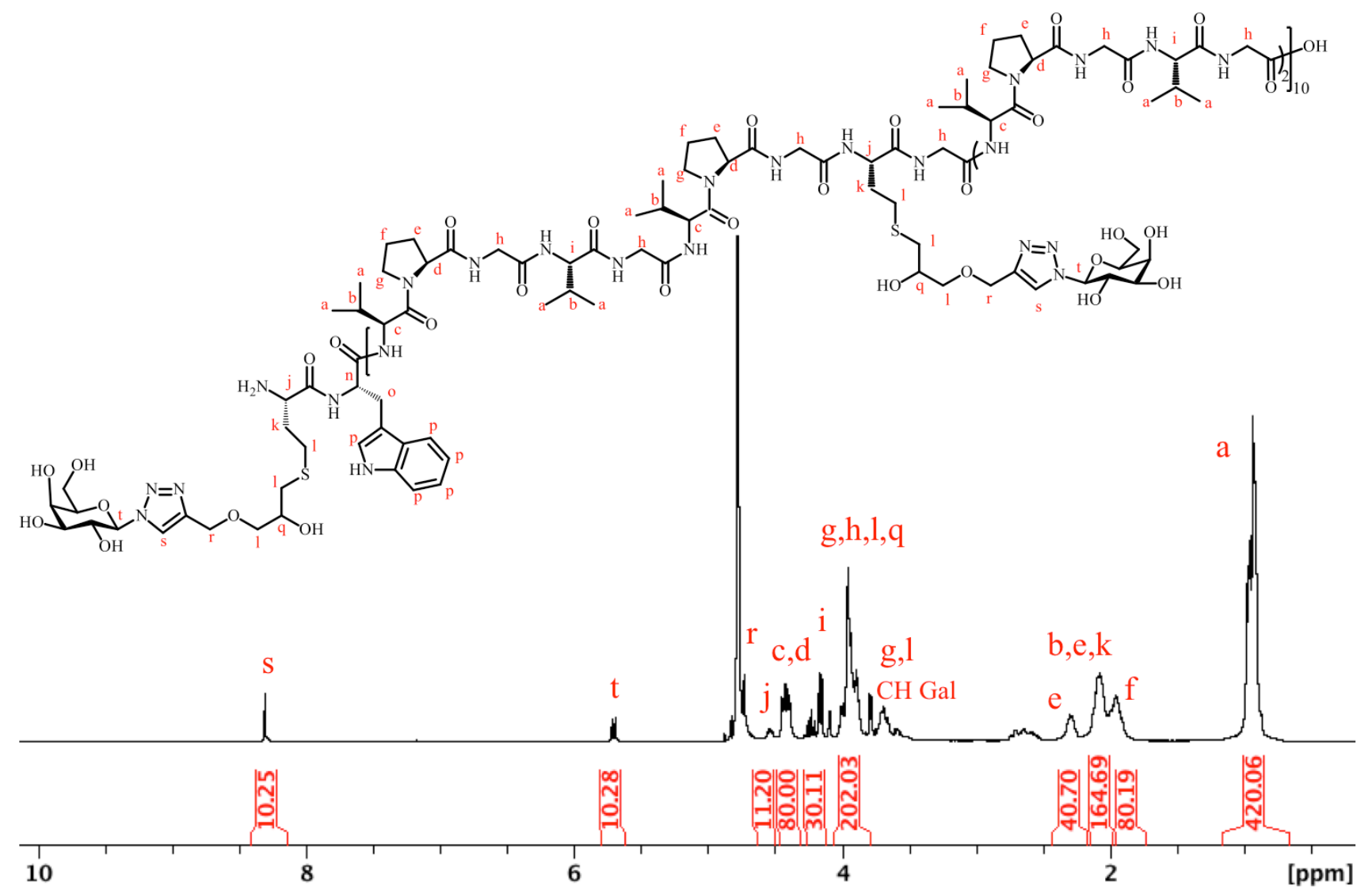

Figure S7. ${ }^{1} \mathrm{H}-\mathrm{NMR}$ spectrum of $\operatorname{ELP}(\mathrm{Gal})$ in $\mathrm{D}_{2} \mathrm{O}$ at $25^{\circ} \mathrm{C}$.

6 


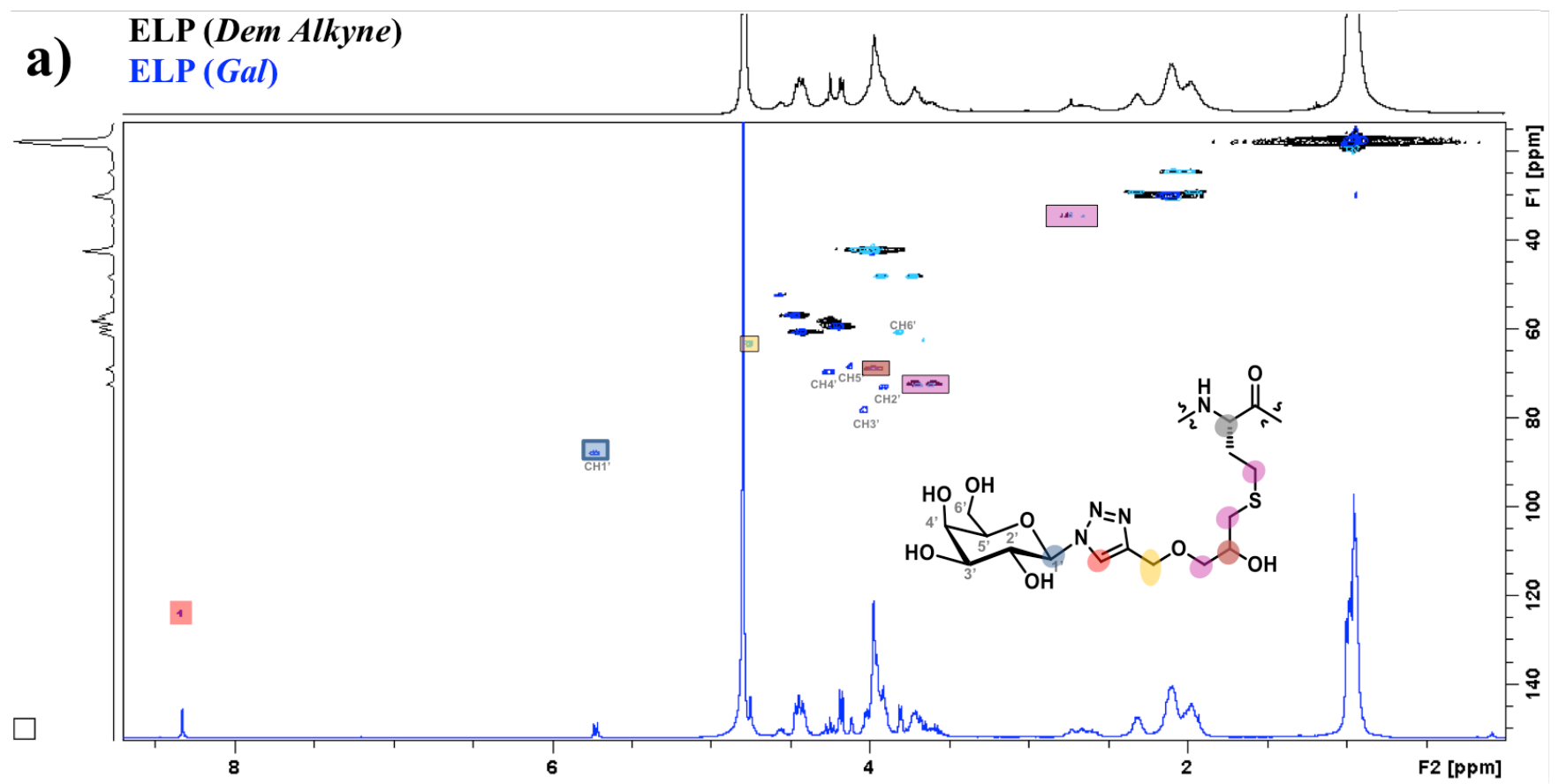

b) Zoom

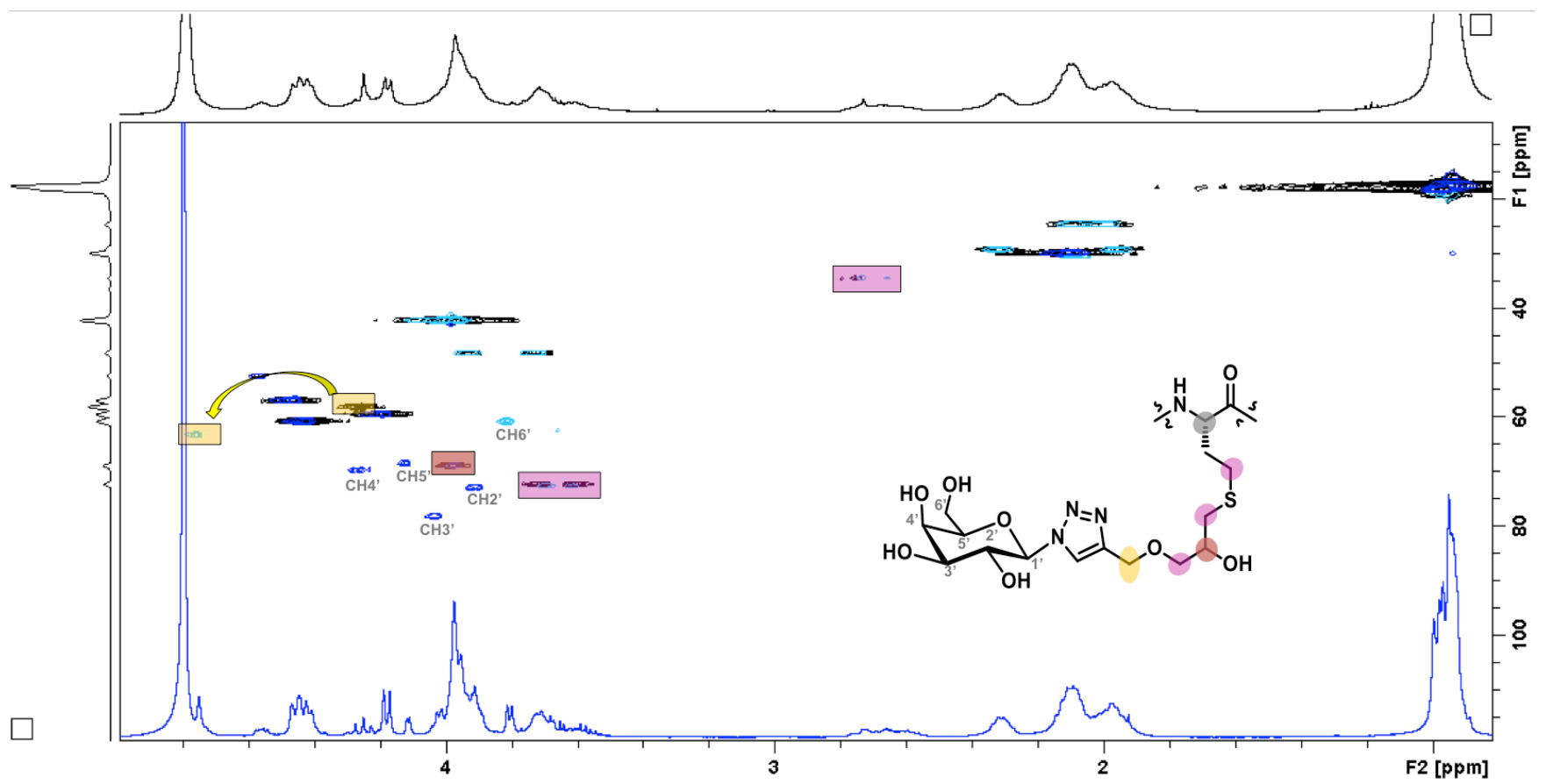

Figure S8. a) Complete HSQC spectra and b) zoom of ELP(Dem Alkyne) (in black) and ELP(Gal) (in blue) in $\mathrm{D}_{2} \mathrm{O}$ at $25^{\circ} \mathrm{C}$. 


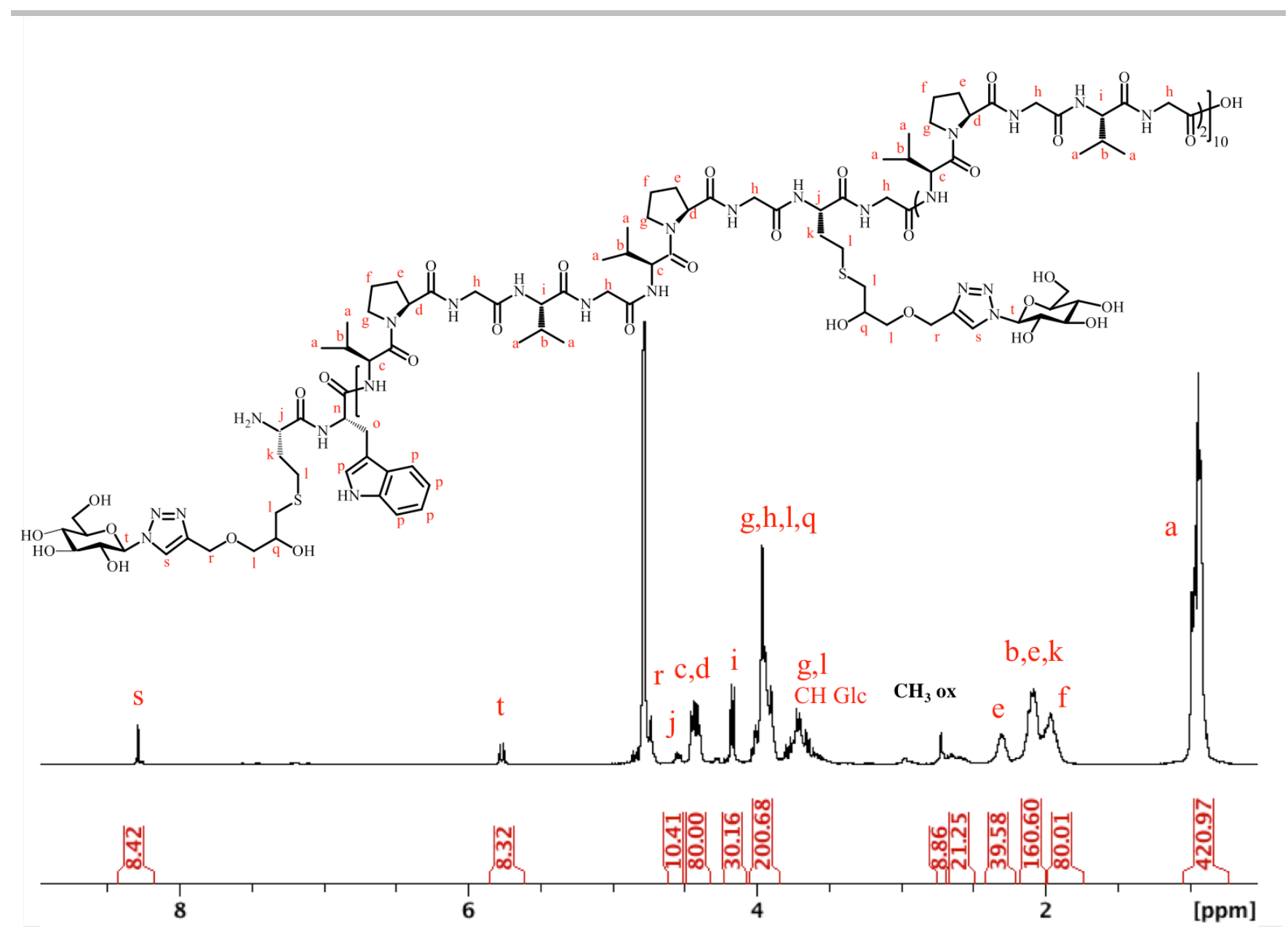




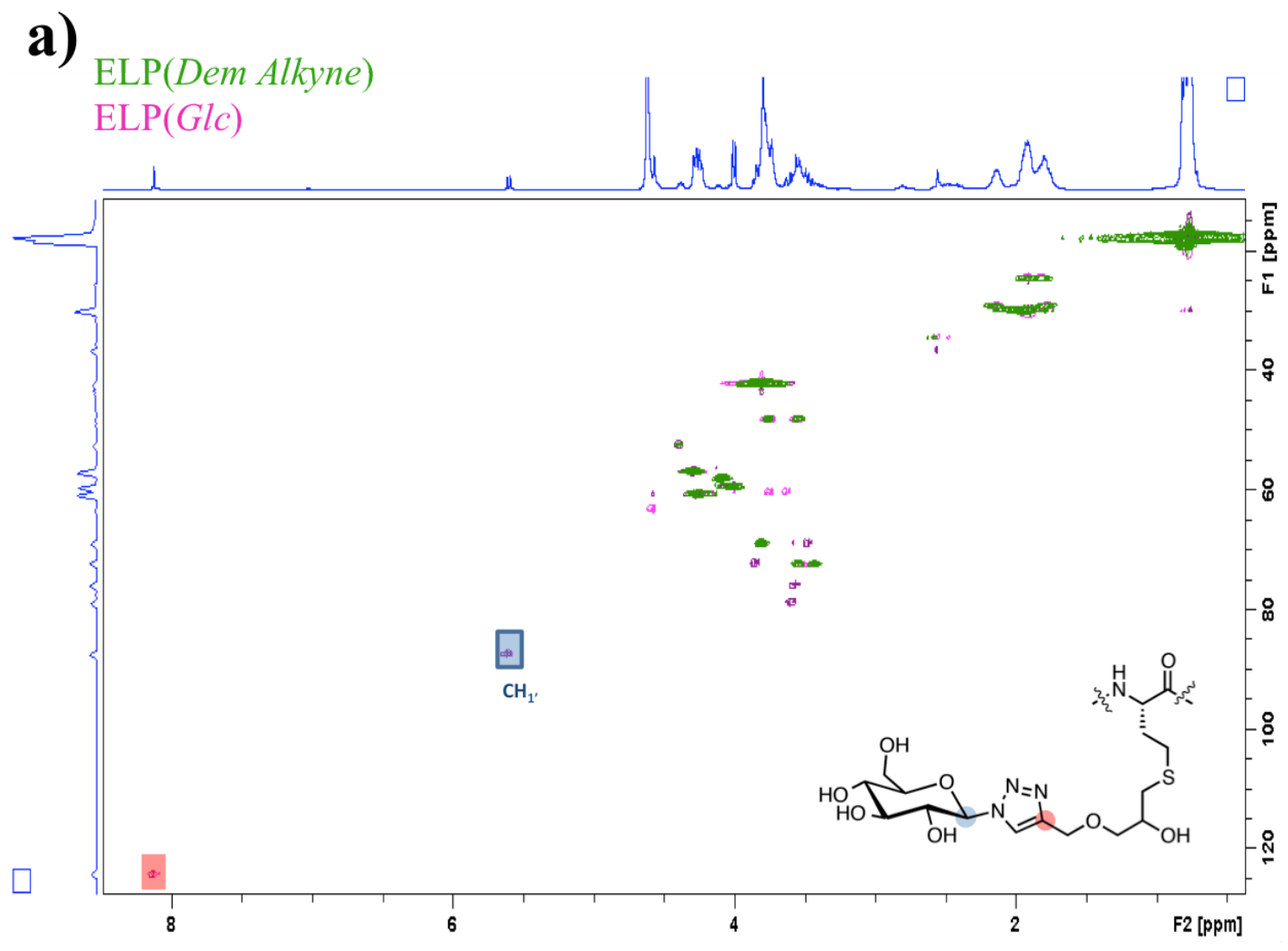

b)

Zoom

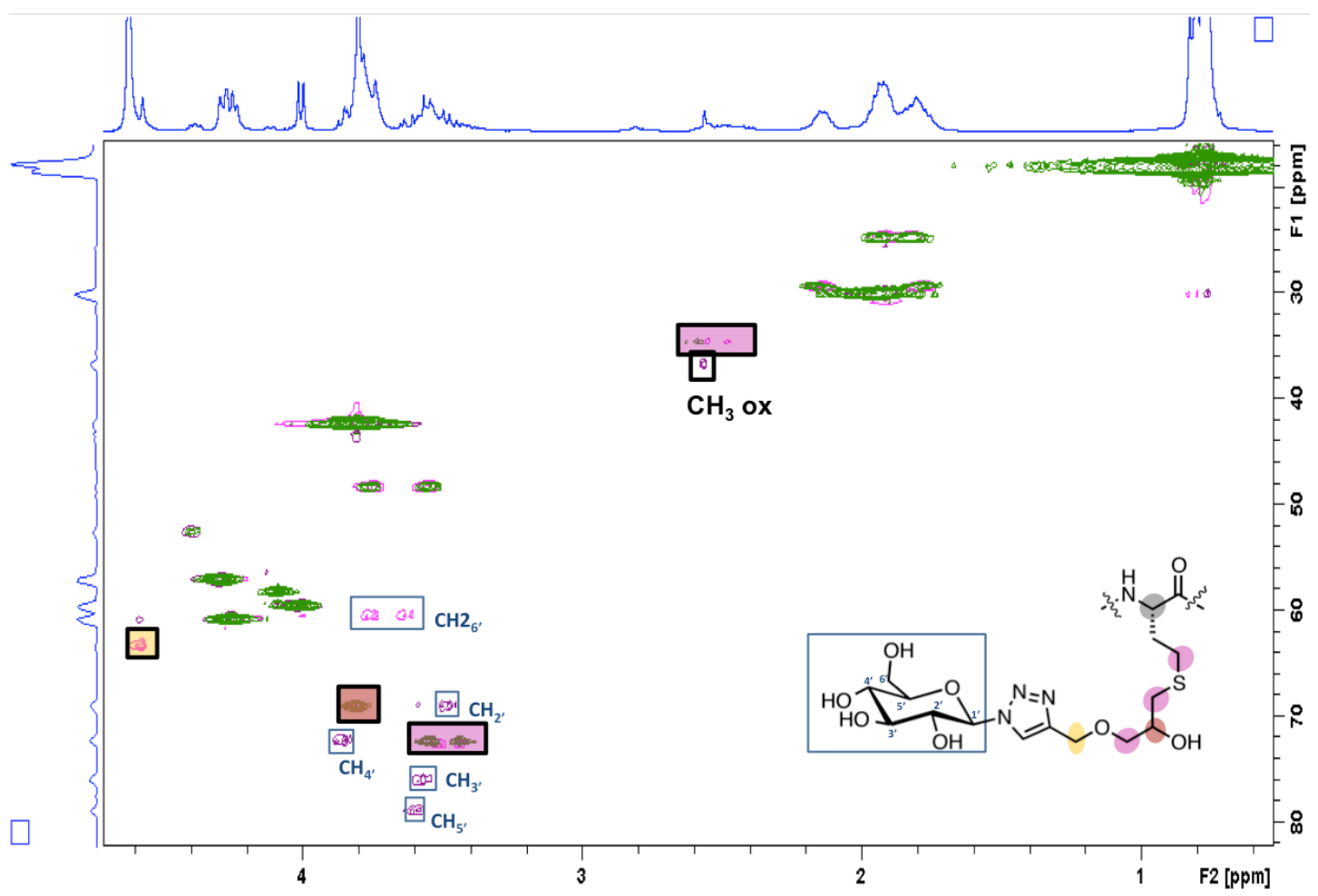

Figure S10. a) Complete HSQC spectra and b) zoom of ELP(Dem Alkyne) and $\operatorname{ELP}(G / C)$ in $\mathrm{D}_{2} \mathrm{O}$ at $25^{\circ} \mathrm{C}$. 
a)

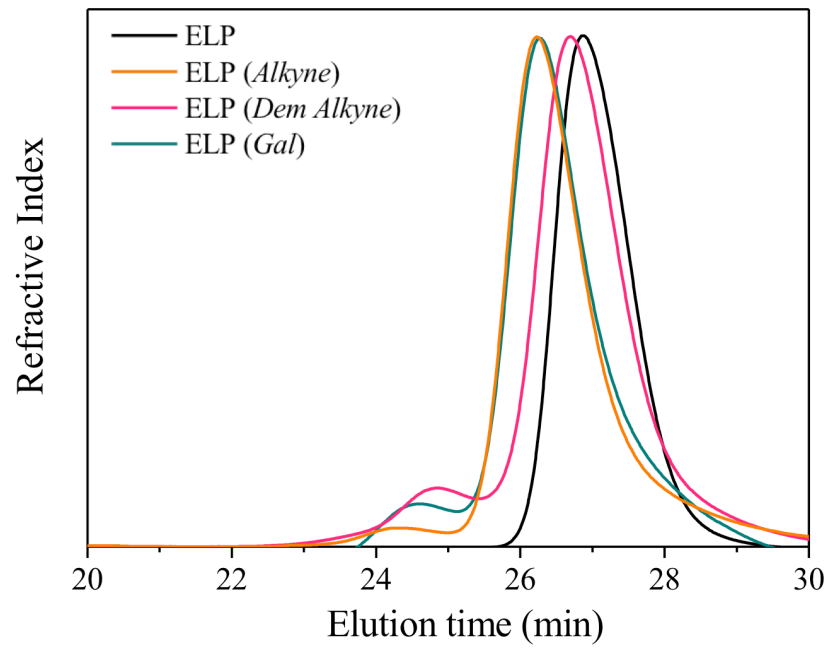

b)

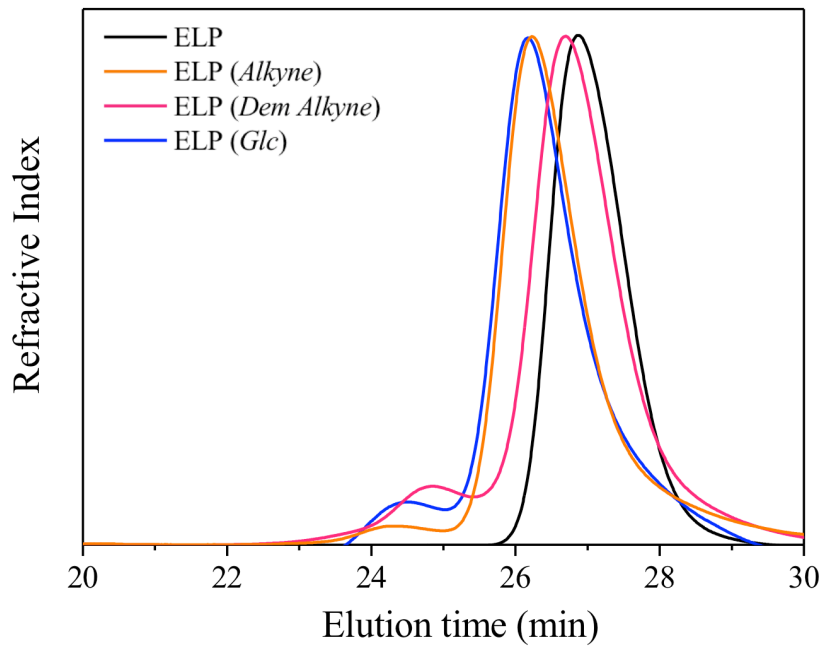

Figure S11. SEC traces in AcOH/ammonium acetate/ACN of ELP (black), ELP(Alkyne) (orange), ELP(Dem Alkyne) (pink) and (a) ELP(Gal) (green) or (b) $\operatorname{ELP}(G / c)$ (blue) using a RI detector.

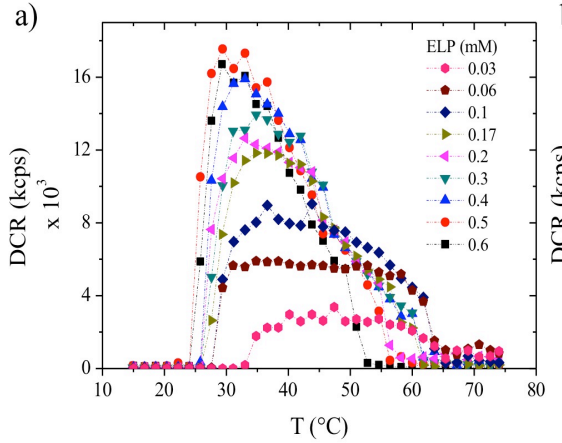

d)

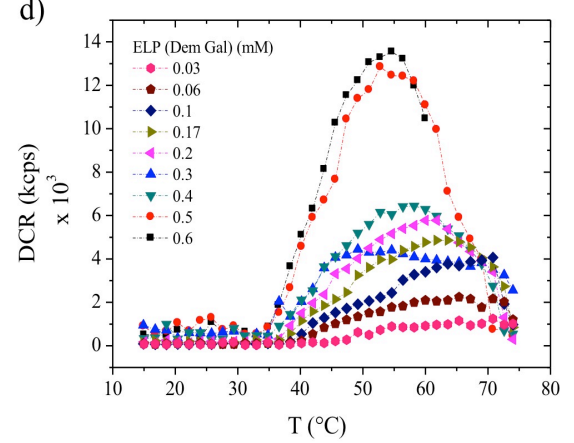

b)

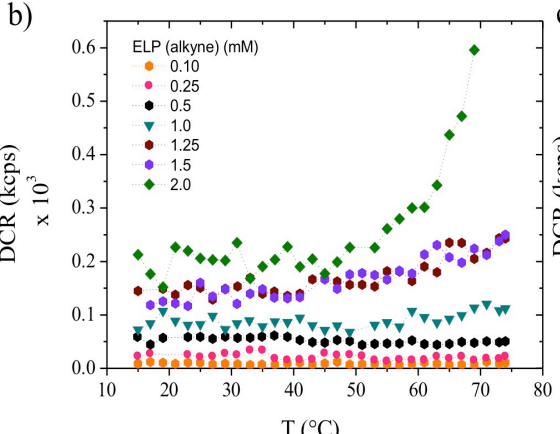

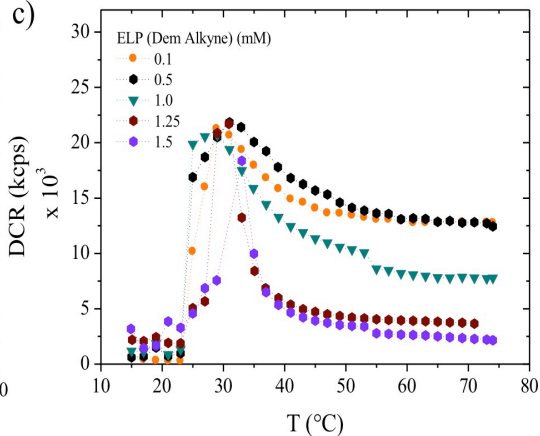

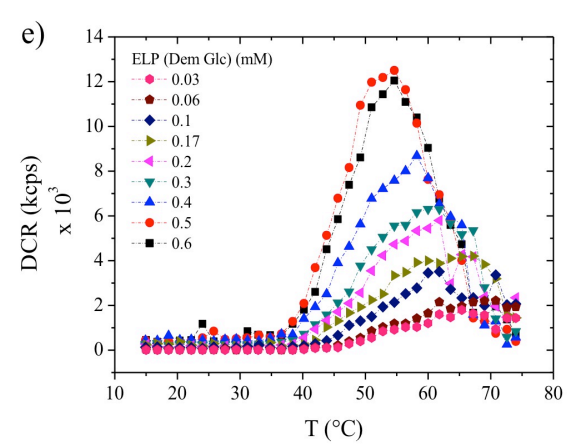

Figure S12. Scattered light intensity as a function of temperature of (a) ELP at concentrations from 0.03 to $0.6 \mathrm{mM}$, (b) ELP(Alkyne) at concentrations from 0.10 to $2.0 \mathrm{mM}$, (c) $\operatorname{ELP}(D e m$ Alkyne) at concentrations from 0.1 to $1.5 \mathrm{mM}$, (d) $\operatorname{ELP}(\mathrm{Gal})$ at concentrations from 0.03 to $0.6 \mathrm{mM}$ and (e) ELP(G/c) at concentrations from 0.03 to $0.6 \mathrm{mM}$, in Trizma buffer ( $50 \mathrm{mM}$ Trizma, $0.15 \mathrm{M} \mathrm{NaCl}$ ). 

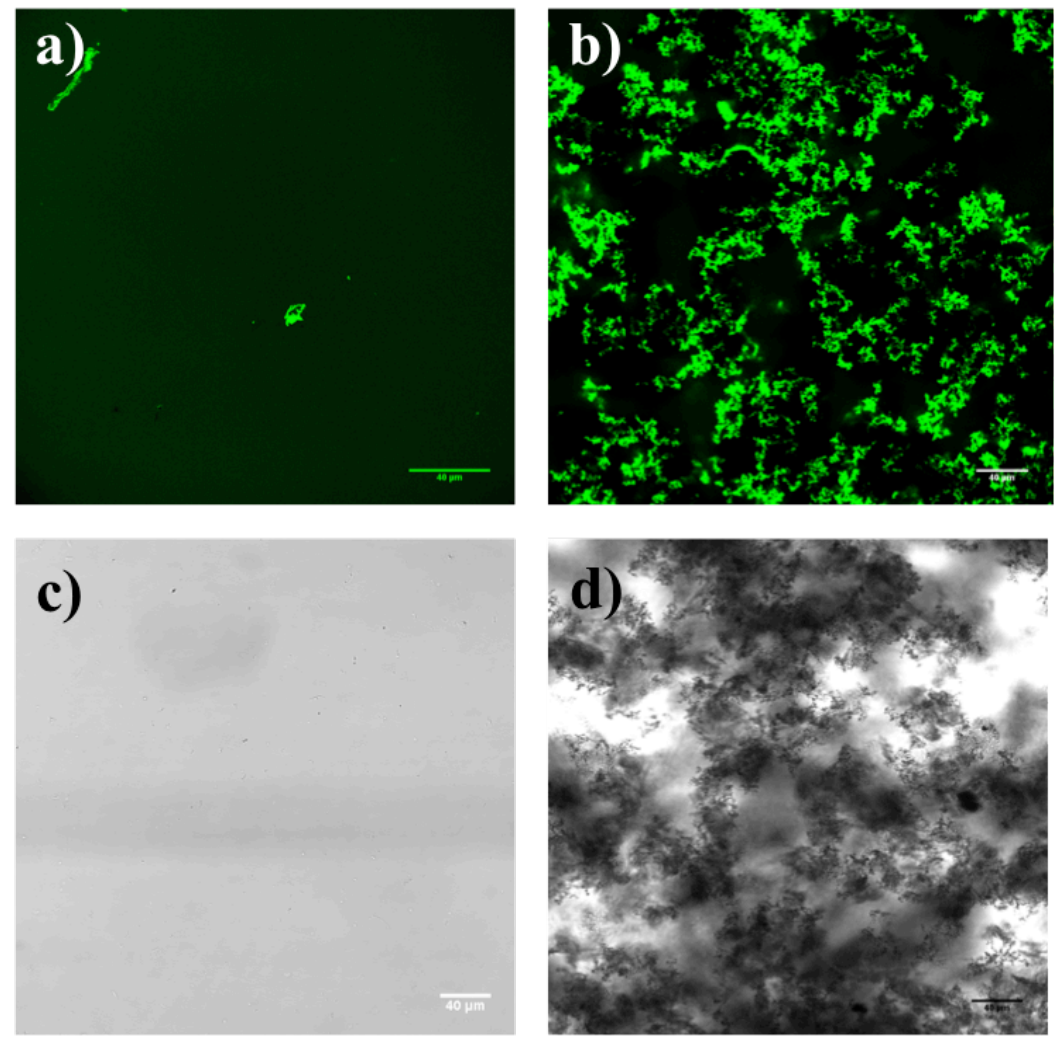

Figure S13. a) Fluorescence microscopy image for $31.2 \mu \mathrm{M} \mathrm{RCA}_{120}$-Fluorescein/200 $\mu \mathrm{M}$ ELP(G/c) (green channel), b) Fluorescence microscopy image for 31.2 $\mu \mathrm{M} \mathrm{RCA}_{120}$-Fluorescein/200 $\mu \mathrm{M} \operatorname{ELP}(\mathrm{Gal})$ (green channel), c) Optical microscopy image for $31.2 \mu \mathrm{M}$ RCA 120 -Fluorescein/ 200 $\mu \mathrm{M}$ ELP(G/c) (transmission), d) Optical microscopy image for $31.2 \mu \mathrm{M} \mathrm{RCA}_{120}$-Fluorescein/ $200 \mu \mathrm{M}$ ELP(Gal) (transmission).
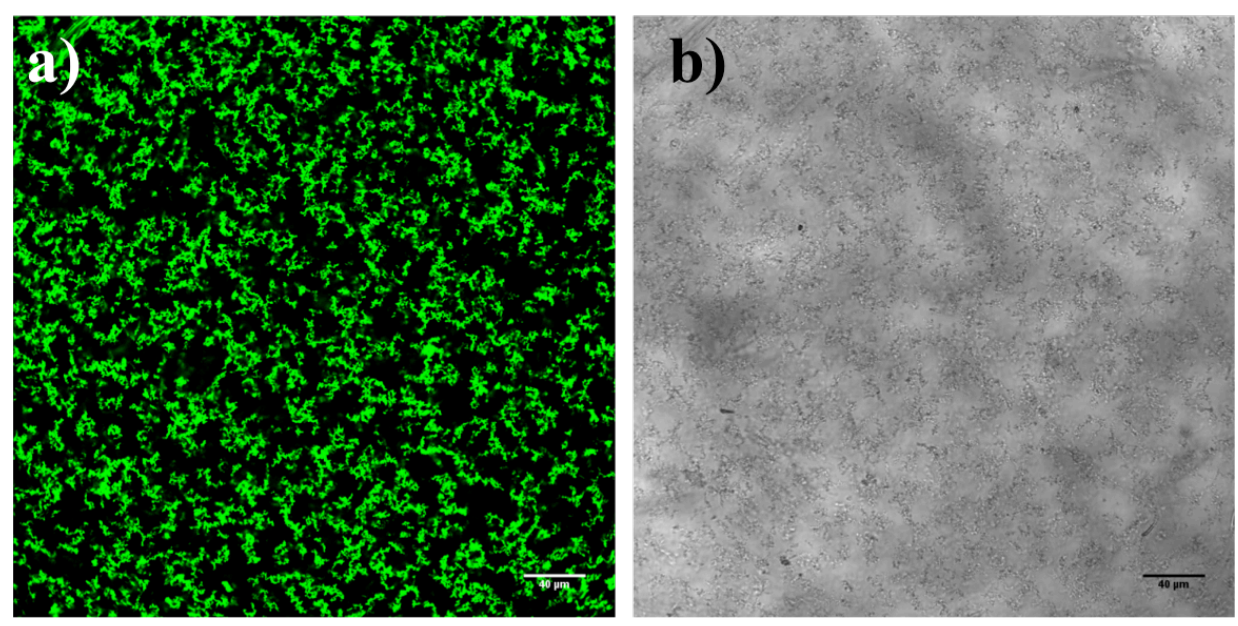

Figure S14. a) Fluorescence microscopy image for $31.2 \mu \mathrm{M} R \mathrm{RA}_{120}$-Fluorescein/ $200 \mu \mathrm{M}$ ELP(Gal) (green channel) in presence of serum, b) optical microscopy image for $31.2 \mu \mathrm{M}$ RCA $120-$ Fluorescein/ $200 \mu \mathrm{M} \mathrm{ELP(Gal)} \mathrm{(transmission)} \mathrm{in} \mathrm{presence} \mathrm{of} \mathrm{serum.}$ 
Table S1. $T_{t}$ values of $\operatorname{ELP}, \operatorname{ELP}(D e m$ Alkyne), $\operatorname{ELP}(G a l)$ and $\operatorname{ELP}(G / c)$ as a function of concentration.

\begin{tabular}{ll}
\hline ELP derivative & $\mathrm{T}_{\mathrm{t}}\left({ }^{\circ} \mathrm{C}\right)$ at $200 \mu \mathrm{M}$ \\
\hline $\operatorname{ELP}$ & 26 \\
$\operatorname{ELP}($ Alkyne $)$ & $>70$ \\
$\operatorname{ELP}($ Dem Alkyne $)$ & 23 \\
$\operatorname{ELP}(\mathrm{Gal})$ & 36 \\
$\operatorname{ELP}(\mathrm{Glc})$ & 38 \\
\hline
\end{tabular}

\section{References}

[1] Petitdemange, R.; Garanger, E.; Bataille, L.; Bathany, K.; Garbay, B.; Deming, T.J.; Lecommandoux, S. Tuning Thermoresponsive Properties of Cationic Elastin-like Polypeptides by Varying Counterions and Side-Chains. Bioconjugate Chem. 2017, 28, 1403-1412.

[2] Anastasaki, A.; Haddleton, A.J.; Zhang, Q.; Simula, A.; Droesbeke, M.; Wilson, P.; Haddleton, D.M. Aqueous Copper-Mediated Living Radical Polymerisation of N-Acryloylmorpholine, SET-LRP in Water. Macromol. Rapid. Commun. 2014, 35, 965-970.

[3] Cavanagh, J. Fairbrother, W.J.; Palmer, A.J.; Skelton, N.J. in Protein NMR Spectroscopy: Principles and Practice, Academic Press, San Diego, CA, 1996.

[4] Wüthrichs K. in NMR of Proteins and Nucleic Acids, Wiley, New York, 1986.

[5] Frénoy, J.-P. ; Tran, A.-T ; Bourrillon, R. Structure and stability of Ricinus communis haemagglutinin. Biochem. J., 1986, $240,227-231$.

[6] Huang, J.; Bonduelle, C.; Thévenot, J.; Lecommandoux, S.; Heise, A. Biologically Active Polymersomes from Amphiphilic Glycopeptides. J. Am. Chem. Soc. 2012, 134, 119-122.

\section{Author Contributions}

T.J.D. and S.L. conceived and designed the experiments. L.M.B.A., R.P., M.R. and E.I. performed the experiments. B.G. designed the genes for ELP production. L.M.B.A., R.P. and E.G. analyzed the data. L.M.B.A., T.J.D. and S.L. wrote the paper, with input from the rest of the authors. S.L. and T.J.D. supervised the research and funding. 